\title{
Improving River Flood Extent Delineation From Synthetic Aperture Radar Using Airborne Laser Altimetry
}

Article

Published Version

Mason, D. C., Horritt, J. T., Dall'Amico, J. T., Scott, T. R. and Bates, P. D. (2007) Improving River Flood Extent Delineation From Synthetic Aperture Radar Using Airborne Laser Altimetry. IEEE TRANSACTIONS ON GEOSCIENCE AND REMOTE SENSING, 45 (12). pp. 3932-3943. ISSN 0196-2892 doi: https://doi.org/10.1109/TGRS.2007.901032 Available at https://centaur.reading.ac.uk/860/

It is advisable to refer to the publisher's version if you intend to cite from the work. See Guidance on citing.

To link to this article DOI: http://dx.doi.org/DOI:10.1109/TGRS.2007.901032

Publisher: IEEE Geoscience and Remote Sensing Society

Publisher statement: (02007 IEEE. Personal use of this material is permitted. However, permission to reprint/republish this material for advertising or promotional purposes or for creating new collective works for resale or redistribution to servers or lists, or to reuse any copyrighted component of this work in other works must be obtained from the IEEE.

All outputs in CentAUR are protected by Intellectual Property Rights law, including copyright law. Copyright and IPR is retained by the creators or other copyright holders. Terms and conditions for use of this material are defined in the End User Agreement. 


\section{www.reading.ac.uk/centaur}

\section{CentAUR}

Central Archive at the University of Reading

Reading's research outputs online 


\author{
David C. Mason, Matthew S. Horritt, Johanna T. Dall'Amico, Tania R. Scott, and Paul D. Bates
}

\begin{abstract}
5 Abstract-Flood extent maps that are derived from synthetic 6 aperture radar (SAR) images provide spatially distributed data 7 for validating hydraulic models of river flood flow. The accuracy of 8 such maps is reduced by a number of factors, including variation 9 in backscatter from the different land cover types that are adjacent 10 to the flood, changes in returns from the water surface that are 11 caused by different meteorological conditions, and the presence of 12 emergent vegetation. This paper describes how improved accuracy 13 can be achieved by modifying an existing flood extent delineation 14 algorithm to use airborne laser altimetry [light detection and 15 ranging (lidar)] as well as SAR data. The lidar data provide an 16 additional constraint that waterline heights should vary smoothly 17 along the flooded reach. The method was tested on a SAR image 18 of a flood for which contemporaneous aerial photography existed, 19 together with lidar data of the unflooded reach. The waterline 20 heights of the SAR flood extent that was conditioned on both SAR 21 and lidar data matched the corresponding heights from the aerial 22 photograph waterline significantly more closely than those from 23 the SAR flood extent that was conditioned only on SAR data. 24 For waterline heights in areas of low slope and vegetation, the 25 root-mean-square error on the height differences reduced from $26 \mathbf{2 2 1 . 1} \mathrm{cm}$ for the latter case to $\mathbf{5 5 . 5} \mathrm{cm}$ for the former.
\end{abstract}

Index Terms-Data fusion, hydrology, lidar, snake.

\section{INTRODUCTION}

29 LOOD extent maps that are derived from remotely sensed 30 data are of considerable use in hydrology, providing spa31 tially distributed data for validation of hydraulic models of river 32 flood flow, for emergency flood relief management, and for 33 development of spatially accurate hazard maps [1], [2]. The all34 weather day-night capability of synthetic aperture radar (SAR) 35 sensors gives these a considerable advantage for flood mapping 36 over sensors operating at visible or infrared wavelengths, as the 37 latter ones are unable to penetrate the cloud that often accom38 panies flood events. This advantage is tempered by the fact that 39 a number of factors conspire to reduce the accuracy of flood 40 maps that are derived from SAR imagery. These include the

Manuscript received October 9, 2006; revised March 26, 2007. This work was supported in part by the EPSRC-funded Flood Risk Management Research Consortium Grant GR/S76394/01.

D. C. Mason, J. T. Dall'Amico, and T. R. Scott are with the Natural Environment Research Council Environmental Systems Science Centre, University of Reading, RG6 6AH Reading, U.K.

M. S. Horritt is with Halcrow Group Ltd., W6 7BY London, U.K

P. D. Bates is with the School of Geographical Sciences, University of Bristol, BS8 1SS Bristol, U.K.

Color versions of one or more of the figures in this paper are available online at http://ieeexplore.ieee.org.

Digital Object Identifier 10.1109/TGRS.2007.901032 substantial variation in backscatter from the different land cover 41 types that are adjacent to the flood, the changes in returns from 42 the water surface that are caused by different meteorological 43 conditions, the presence of emergent vegetation, and the effects 44 of man-made structures in urban areas. This paper describes 45 a study to reduce inaccuracies from some of these sources 46 in an existing flood extent delineation algorithm by using an 47 additional data source, namely, airborne laser altimetry.

The simplest model of SAR backscatter from a river flood 49 assumes that the water surface is smoother than the surrounding 50 land and acts as a specular reflector, reflecting radiation away 51 from a side-looking sensor, so that the water appears dark 52 compared to the land. Two factors complicating the simple 53 specular reflection model in practice are the effects of wind 54 or rain roughening of the water surface, and emergent vege- 55 tation. The relationship between SAR backscatter and surface 56 roughness that is caused by wind blowing over the oceans is 57 well understood [3], and the effect may raise the backscatter 58 from the water to similar or greater levels than the adjacent 59 land [4], [5]. Wind roughening of a river flood surface can give 60 rise to similar effects, but these can have substantial spatial 61 variation, depending on the local topography, which determines 62 the fetch for a given wind direction. The presence of emergent 63 vegetation can give rise to multiple reflections between the 64 water and the vegetation, leading to a substantial enhance- 65 ment of backscatter, the magnitude of which is a function 66 of radar wavelength, look angle, and polarization. The effect 67 has been observed in a number of studies of flooded forest 68 and marshland (e.g., [6]-[9]), and the increase in backscatter 69 has been modeled mathematically in [10]. Enhanced backscat- 70 ter from the water surface that is caused by wind roughen- 71 ing or emergent vegetation will also result in an increased 72 level of noise due to the multiplicative nature of noise in 73 SAR images.

A number of methods for the automated delineation of flood 75 extent in SAR imagery of both fluvial and tidal environments 76 have been developed [4], [5], [9], [11]-[21]. Several of these 77 studies have illustrated the great potential of SAR sensors for 78 synoptic observation of large flooding events. An automatic 79 technique for delineating a fluvial flood using a statistical 80 active contour model (or snake) that is applied to a SAR 81 image to identify areas of homogeneous speckle statistics is 82 described in [18] and [19]. This assumes that single-frequency 83 single-polarization SAR intensities are available and was aimed 84 at producing an observed flood extent against which to validate 85 
86 a modeled flood extent. Due to the difficulties of imaging urban 87 areas using SAR, its use is limited to large-area mapping of 88 floods in rural areas. The SAR segmentation uses both local 89 tone and texture measures, and is capable of accurate feature 90 boundary representation. The method was applied to a flood 91 that was imaged using the ERS-1 satellite SAR sensor and 92 proven to be capable of identifying $75 \%$ of the flooded area 93 correctly, with $70 \%$ of the waterline coinciding with ground 94 data within $20 \mathrm{~m}$. The main error in waterline position was 95 found to be due to unflooded short vegetation that was adjacent 96 to the flood giving similar radar returns to open water, causing 97 an overestimation of flood extent. The loss of flood extent due 98 to emergent vegetation was found to be a secondary source 99 of error.

100 Further work on this topic [22], [23] found that, as a result of 101 these error sources and the relatively large size of the European 102 Remote Sensing Satellite (ERS) SAR pixel, the heights of the 103 SAR waterline along a flooded reach could sometimes be in 104 error by several meters (although, generally, it was much less) 105 and could exhibit significant noise. One reason for this was that 106 there was no constraint that the waterline heights should vary 107 smoothly along the reach, whereas, in reality, the longitudinal 108 slope of typical flood flows is low $\left(\sim 0.001-0.0001 \mathrm{~m} \cdot \mathrm{m}^{-1}\right)$, 109 and changes in slope are very gradual. With this level of dif110 ferences, the SAR image becomes much less useful for model 111 flood extent validation than it could otherwise be.

112 Horritt et al. [19] point out that their flood extent map113 ping procedure identifying the flood as a region of rela114 tively homogeneous speckle statistics may be improved by 115 the adoption of a model-based approach. In this vein, this 116 paper describes the use of light detection and ranging (li117 dar) data to modify the SAR waterline, so that it becomes 118 more useful for validation. The snake algorithm [18], [19] 119 is modified to look not only at SAR image space but also 120 at lidar digital terrain model (DTM) and vegetation height 121 maps, so that the snake can be conditioned to be smoothly 122 varying in ground height as well as in SAR intensities and 123 textures. This should reduce errors that are caused by un124 flooded vegetation that is adjacent to the flood giving similar 125 returns to open water and also errors due to the SAR pixel 126 size. It could also help somewhat in reducing errors due to 127 emergent vegetation. An additional benefit of producing a 128 more smoothly varying waterline is that it may allow the 129 development of improved performance measures for flood ex130 tent validation based on patterns of height differences rather 131 than on patterns of wet or dry pixels, as currently done [24]. 132 The algorithm specifically sets out to improve the vertical 133 accuracy of the SAR waterline, although any improvement 134 should also lead to improvement in the horizontal waterline 135 accuracy due to their correlations that are contained within 136 the DTM.

137 Used in this way, the lidar data may actually play a dual 138 role in the modeling process, as lidar is often used to pa139 rameterize the hydraulic model being validated, with the li140 dar DTM providing the model bathymetry and possibly the 141 vegetation heights being used to estimate bottom friction 142 [22]. However, the use of lidar data in SAR waterline ex143 traction as well as model parameterization does not under-

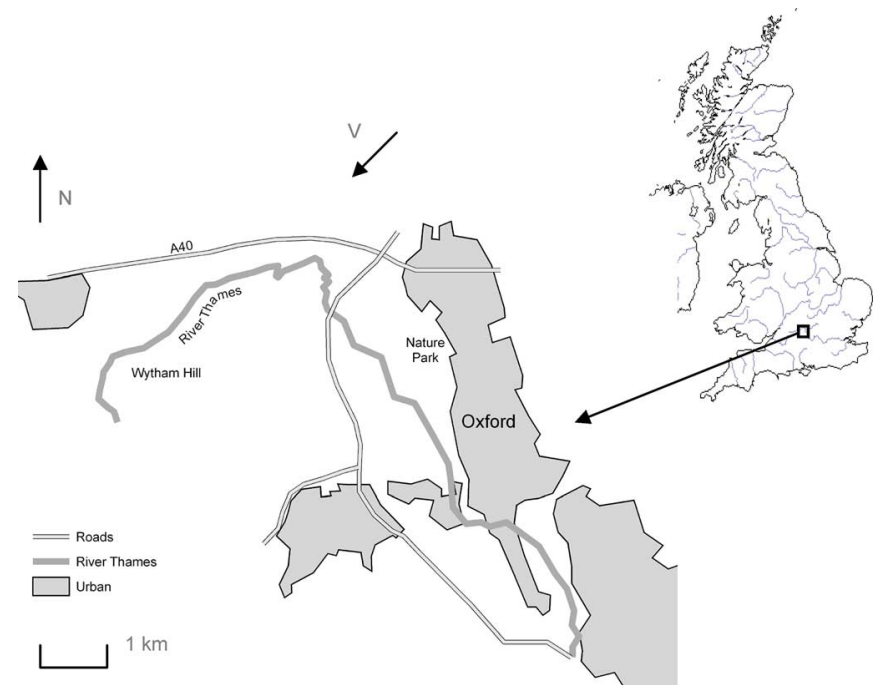

Fig. 1. Location of the test area.

mine the independence of the SAR waterline in the validation 144 process.

\section{Test Data SET}

146

An ideal data set on which to validate the method would be 147 from a flood for which both satellite SAR data and simultaneous 148 aerial photography were available, so that the SAR snake 149 waterlines that are conditioned without and with the lidar data 150 could be compared with the waterline from the aerial pho- 151 tographs. In addition, lidar data of the unflooded area should be 152 available.

Biggin and Blyth [25] acquired oblique aerial photos of a 154 flood on the Thames west of Oxford, U.K., on December 4, 155 1992, at the same time (to within $2 \mathrm{~h}$ ) as an ERS-1 SAR 156 overpass of the area. The Thames is a low-relief slow-response 157 catchment, and at this point along its course, the river discharge 158 during a flood changes only very gradually, so that such timing 159 differences are unimportant. The peak discharge for this event 160 was measured at $76 \mathrm{~m}^{3} \cdot \mathrm{s}^{-1}$, which represents a $\sim 1$-in-5-year- 161 recurrence interval flow. The ERS-1 SAR image was acquired 162 approximately $36 \mathrm{~h}$ after the flood peak when the discharge had 163 dropped to $73 \mathrm{~m}^{3} \cdot \mathrm{s}^{-1}$, indicating the very slow response of the 164 catchment. At the time of overpass, there was no wind or rain in 165 the area. The location of the test area is shown in Fig. 1, and an 166 example of the aerial photography is shown in Fig. 2. The flood- 167 plain over this reach is semirural, with the majority of fields 168 being used at the time for pasture or having been ploughed. 169 There are also several urban areas, and the region is crossed 170 by a number of major roads and railways. The flood waterline 171 was delineated by eye from the aerial photos and vectorized 172 [19]. The waterline vectors were then georeferenced using an 173 orthographic transform that is parameterized by a least squares 174 method using 15-20 control points for each photograph. The 175 error in the waterline position was assessed from waterline 176 segments where the waterline was observed to lie alongside a 177 hedgerow or field boundary that could be located on a 1:25000 178 scale map and was found to be less than $20 \mathrm{~m}$. 


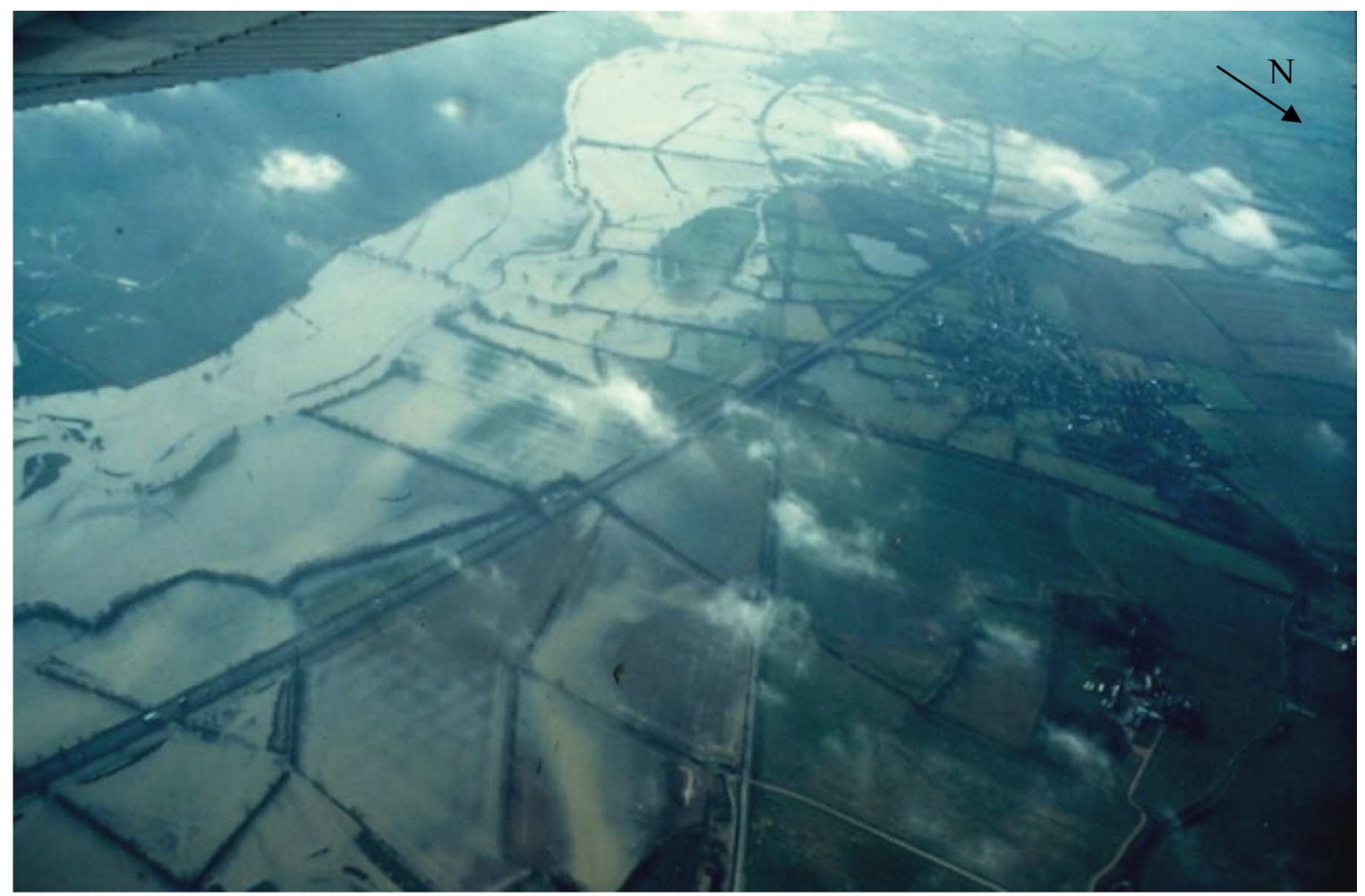

Fig. 2. Example of the aerial photography in the upper section of the reach, looking southwest from the north of the region (the view direction is $\mathrm{V}$ in Fig. 1).

180 Lidar data at 1-m resolution were acquired for a section 181 of this reach west of Oxford and approximately $12 \mathrm{~km}$ long 182 by the Environment Agency of England and Wales (EA). The 183 lidar was an Optech ALTM 2033 that was flown on a Cessna 184 aircraft at $120 \mathrm{kn}$ at a flying height of $900 \mathrm{~m}$, with a laser 185 firing rate of $33 \mathrm{kHz}$, a scanning frequency of $30 \mathrm{~Hz}$, and a 186 scanner half angle of $18^{\circ}$. The lidar heights were validated by 187 the EA by comparing them with a set of global positioning 188 system (GPS) heights of several flat unvegetated surfaces in 189 the area. Based on a sample of 299 GPS readings, the lidar 190 heights were found to have an rms error of $10.6 \mathrm{~cm}$, which 191 comprised a random error of $10.2 \mathrm{~cm}$ and a systematic error 192 of $2.6 \mathrm{~cm}$. Lidar height accuracy reduces on steeper slopes 193 and in vegetated regions [26]. Lidar positional accuracy was 194 about $0.4 \mathrm{~m}$ [27]. The postprocessed lidar DTM and vege195 tation height mask were obtained from the EA. These were 196 degraded to 2-m pixel size to avoid too large a mismatch 197 with the SAR pixel size of $12.5 \mathrm{~m}$. Fig. 3 shows the lidar 198 DTM with the high land of Wytham Hill in the west and the 199 raised Oxford Nature Park in the east (see Fig. 1), both of 200 which are relevant to this study. Fig. 3 also shows the aerial 201 photo waterline overlain on the lidar DTM, with the waterline 202 color representing its difference in height from the local mean 203 waterline height (within $0.5-\mathrm{km}$ distance). The presence of 204 large sections of waterline having small differences (blue color) 205 from the local mean height indicates that the aerial waterline 206 height varies smoothly along the reach. The waterline includes 207 instances of islands of higher ground that are surrounded by 208 water. It is assumed here that all areas of water have been 209 accurately mapped, so that the validation data are essentially 210 error free.

\section{Flood Extent Extraction From SAR Data}

\section{A. Algorithm Description}

A detailed description of the algorithm to delineate a flood 213 using an active contour model is given in [18], and only an 214 overview is presented here. Active contour models or snakes 215 are useful for converting incomplete or noisy edge maps into 216 smooth continuous vector boundaries [5], [28]. The edge image 217 space is searched using a dynamic curvilinear contour that is 218 driven to be attracted to edge pixels using an energy minimiza- 219 tion function, so that the contour can link together unconnected 220 edge segments. The contour (snake) is represented in a piece- 221 wise linear fashion as a set of nodes (i.e., the coordinates of the 222 snake points) that are linked by straight-line segments. Ivins 223 and Porrill [29] developed a statistical snake that operates on 224 the image itself rather than an edge image, dispensing with the 225 need for a prior edge detection stage. Their technique involves 226 estimating the local image mean intensity (tone) at a node using 227 the pixels between this node and its adjacent nodes. This gives 228 the advantage that noise due to SAR speckle is reduced by 229 averaging pixel intensities along an edge while, at the same 230 time, maintaining resolution that is perpendicular to the edge, 231 giving accurate edge positioning. The local intensity variance 232 (texture) is also calculated from these pixels, as this has proven 233 to be a useful discriminator between different natural land- 234 cover types having similar mean intensities in SAR imagery. 235

The statistical snake is formulated as an energy minimization 236 problem with the total snake energy $E(\boldsymbol{u}(s))$ given by

$E(\boldsymbol{u}(s))=E_{\text {tension }}+E_{\text {curvature }}-\iint G(I(x, y)) d x d y$ 


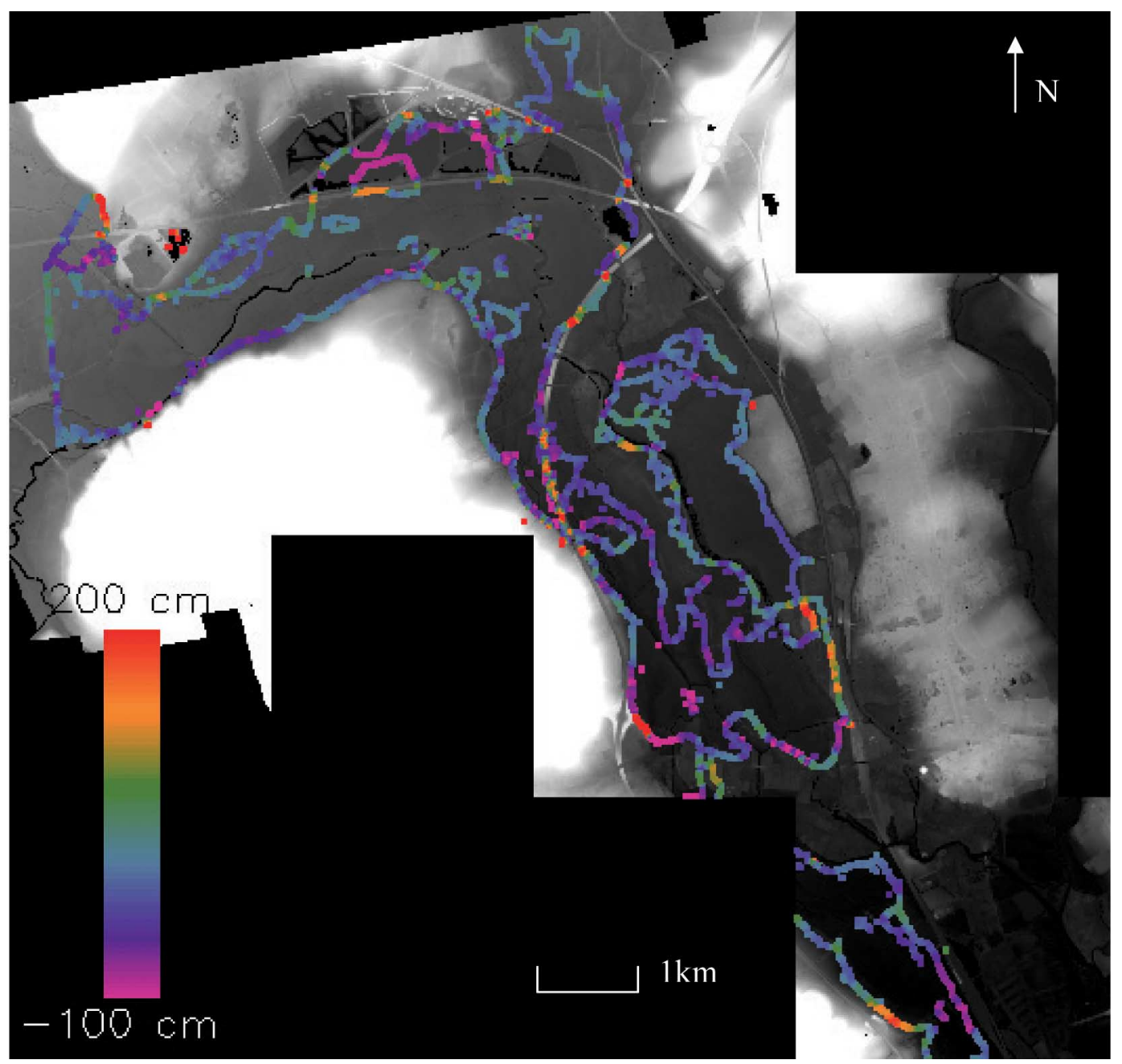

Fig. 3. Aerial photo waterline overlain on the lidar DTM. The colors represent the difference in height of the waterline from the local mean waterline height.

238 where $\boldsymbol{u}(s)=(x(s), y(s))$ describes the contour position $(x, y)$ 239 in the 2-D image space as a vector function of arc length 240 parameter $s$. $E_{\text {tension }}$ and $E_{\text {curvature }}$ are energies that are gen241 erated by the model's internal tension and stiffness constraints, 242 which favor a smooth uncrenellated contour that is made up 243 of evenly spaced nodes (see the following). $G$ is a goodness 244 function that assesses how well a set of image pixels $I(x, y)$ 245 meets certain criteria. The total energy is minimized if the con246 tour encloses a region of pixels that is homogeneous in tone and 247 texture.

248 If the mean and variance of the intensities of the set of pixels 249 that are immediately at either side of a particular snake node are 250 measured, the knowledge of how these variables are distributed 251 can be used to estimate the probability that these pixels match 252 those that are already within the region that is enclosed by the 253 contour. Horritt [18] relates $G$ to the $\log$ of this probability, with 254 the dependence on the measured sample mean $\mu^{\prime}$, for example, 255 having the form

$$
G\left(\mu^{\prime}\right)=1-n\left(\mu^{\prime}-\mu\right)^{2} / v k^{2}
$$

256 where $\mu$ and $v$ are the mean and variance of the seed population 257 that is already enclosed within the contour, respectively; $n$ is the sample size; and $k$ is a parameter that can be adjusted 258 to tune algorithm performance. $G$ is then equal to 1 for a 259 set of pixels with the expected mean but falls to zero if the 260 mean differs by $k \sqrt{ }(v / n)$ (i.e., $k$ standard deviations) from 261 the expected value. The parameter $k$ is usually set at about 262 2 or 3 but may be increased further to allow for a level of 263 statistical inhomogeneity in the region being segmented. The 264 overall goodness function (with components that are based on 265 both the measured mean and variance) is limited to a minimum 266 value of -1 .

The roles of the tension and curvature constraints are to pro- 268 duce a contour of appropriate smoothness with evenly spaced 269 nodes, by a consideration of the balance between image and 270 curvature forces. Consider the situation that is shown in Fig. 4271 for snake nodes at $\boldsymbol{u}_{i-1}, \boldsymbol{u}_{i}$, and $\boldsymbol{u}_{i+1}$ that are linked by unit 272 vectors $\boldsymbol{v}_{i}$ and $\boldsymbol{v}_{i+1}$. The local curvature is $\Delta \theta / \Delta s$, where $\Delta \theta 273$ is the change of angle along arc length $\Delta s$. Horritt [18] gives 274 the contribution to the total curvature energy as

$$
\Delta E_{\text {curvature }}=\gamma(\Delta \theta / \Delta s)^{2} / \Delta s=\gamma\left|\boldsymbol{v}_{i+1}-\boldsymbol{v}_{i}\right|^{2} / a_{i}
$$

where $a_{i}$ is the distance between the midpoints of $\boldsymbol{v}_{i}$ and $\boldsymbol{v}_{i+1}, 276$ and $\gamma$ is a curvature energy weighting parameter. Equation (3) 277 


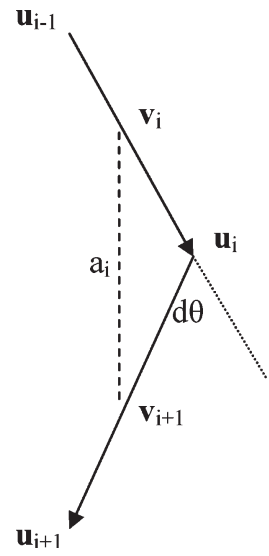

Fig. 4. Vectors for describing curvature and tension energies (after [18]).

278 is valid for small values of $\Delta \theta$. Similarly, the contribution to 279 the tension energy is given by

$$
\Delta E_{\text {tension }}=\lambda\left(\left|\boldsymbol{u}_{i+1}-\boldsymbol{u}_{i}\right|^{2}+\left|\boldsymbol{u}_{i}-\boldsymbol{u}_{i-1}\right|^{2}\right)
$$

280 where $\lambda$ is the tension energy weighting parameter. The mag281 nitudes of these energies can be adjusted using the weighting 282 parameters. Too large a value for the curvature parameter 283 will make the curvature term dominate the model energy and 284 produce an unrealistically smooth contour. Too large a value of 285 the tension parameter will favor a short contour and stifle the 286 growth of the snake.

287 The scheme that was used to minimize the energy is the 288 algorithm of Williams and Shah [28]. For each node at each 289 iteration, the change in energy $d E$ is computed for moves to all 290 eight neighbors of the node

$$
d E=-G d A+d E_{\text {tension }}+d E_{\text {curvature }}
$$

291 The lowest (most negative) $d E$ is chosen. Obviously, $d E$ is 292 equal to zero for no node movement. $G$ is calculated along the 293 line segments linking the node with its two neighbors, and $d A$ is 294 the local change in area. If $G$ is positive, the snake is in a region 295 of homogeneous pixels, a positive $d A$ is favored, and the snake 296 expands. If $G$ is negative, the snake is in an inhomogeneous re297 gion, a negative $d A$ is favored, and the snake retreats. The mean 298 and standard deviation of the seed population are calculated 299 from all pixels lying inside the contour every ten iterations.

300 The flooded region may not be simply connected, as islands 301 and isolated water bodies may form holes and outliers. To cope 302 with this, the algorithm incorporates a method for dealing with 303 complex topology and snake self-intersection. As an example, 304 a snake may spawn a smaller subsnake within itself to represent 305 an island.

\section{B. Implementation and Qualitative Assessment of Results}

307 A personal computer (PC)-based implementation of the al308 gorithm (Psnake NT) was used in this paper [30]. Psnake NT 309 is a software package that is available to the hydrological 310 modeling community for the semiautomatic extraction of flood

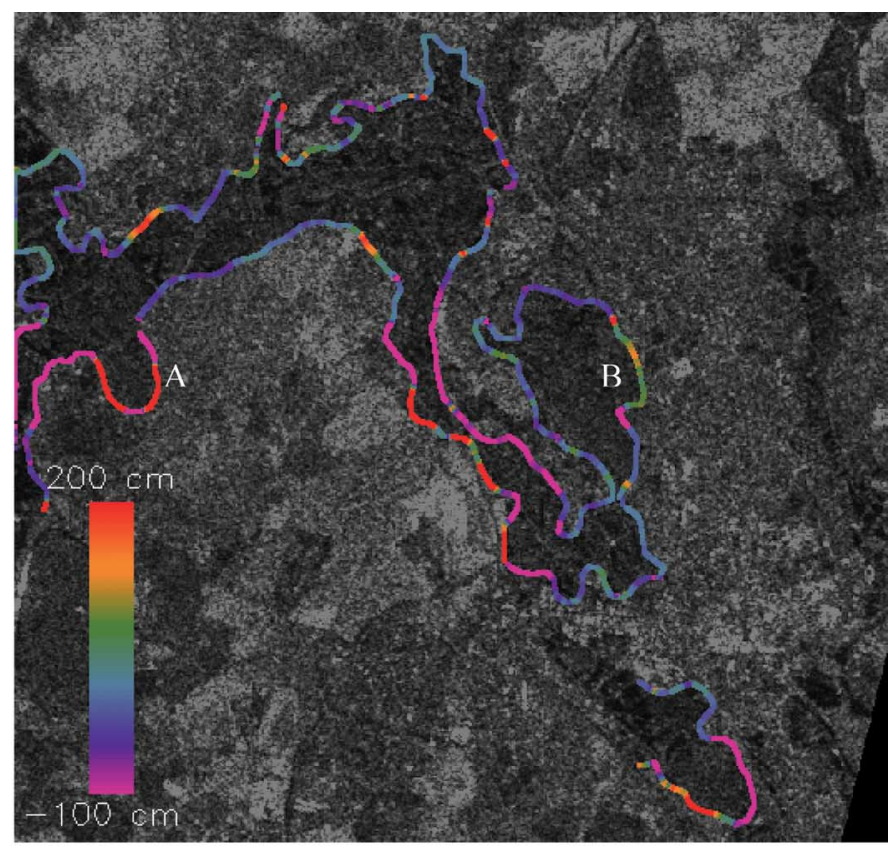

(a)

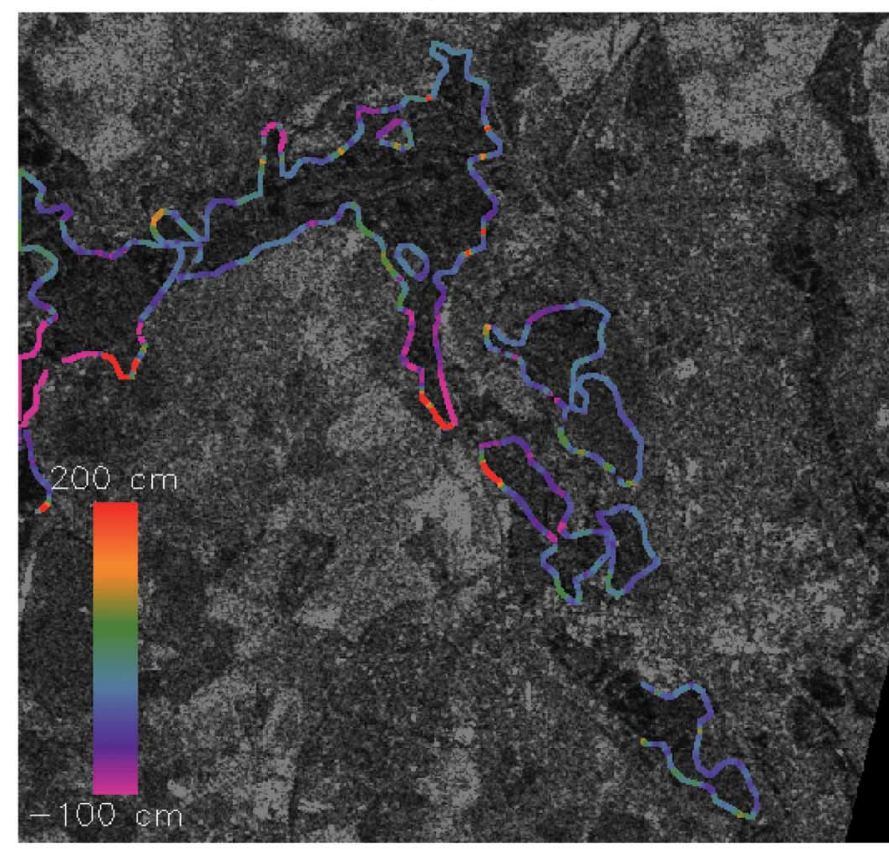

(b)

Fig. 5. Waterline conditioned only on SAR data overlain on SAR data (a) for parameter $k=3$ and (b) $k=2$. The colors represent the difference in height of the waterline from the local mean waterline height.

extents from SAR data. Fig. 5 shows snake waterlines that are 311 generated using SAR data only, for the number of standard 312 deviations $k$ of 3 and 2, overlain on SAR data. It has been found 313 by experiment that $k$ is probably the most important parameter 314 controlling the snake [19]. Other parameter settings were a 315 minimum node spacing of 6 pixels, a maximum node spacing 316 of 12 pixels, curvature parameter $\gamma$ of 68.3 , tension parameter $\lambda 317$ of 0.1 , a texture weight of 0.2 , and iterations of 200 . The snake 318 was seeded (i.e., initialized) manually as a narrow strip lying 319 


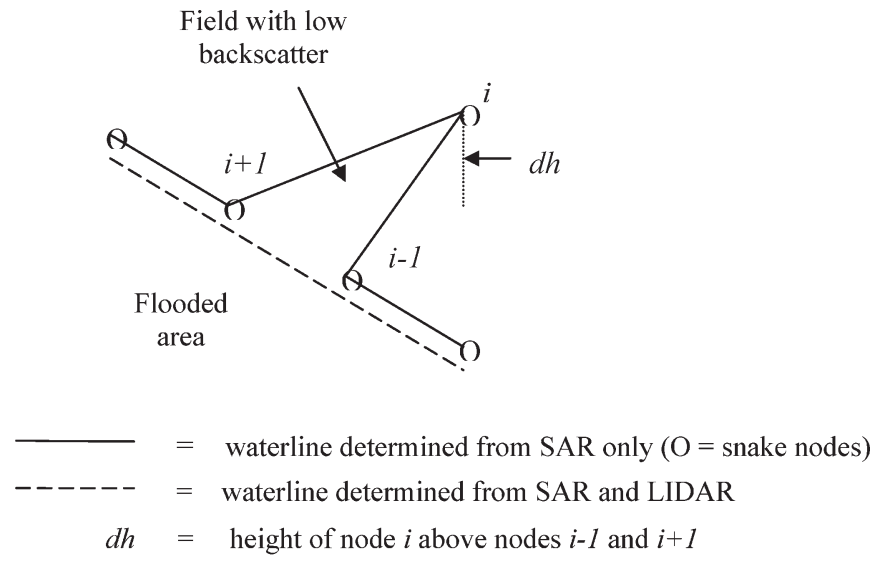

Fig. 6. Example error that might be corrected using lidar.

320 along the course of the unflooded river channel, ensuring that 321 it contained only flooded pixels.

322 In Fig. 5, the snake shows a tendency to leak onto higher 323 ground on Wytham Hill [point A in Fig. 5(a), see also Fig. 3]. 324 This is likely to be due to the presence of vegetated fields, 325 which correspond to areas of low SAR backscatter and are 326 likely to be misclassified as flooded. While no ground reference 327 data were acquired at the time of the flood, evidence for this 328 comes from a recent aerial photograph that was obtained later 329 than the SAR image. A further example of leakage of the snake 330 onto higher ground is visible at point B in Fig. 5(a), where 331 the snake has leaked onto the Oxford Nature Park, which is 332 higher than the land toward the Thames yet again exhibits low 333 SAR backscatter.

\section{$334 \quad$ IV. Flood EXTENT EXTRACTION FROM \\ $335 \quad$ SAR AND LIDAR DATA}

\section{A. Algorithm Modification}

337 The snake algorithm was modified so that the snake was 338 conditioned not only on the SAR image but also on the lidar 339 DTM, so that it becomes smoothly varying in ground height as 340 well as in SAR intensities and textures. The principle that was 341 adopted was that the SAR image should still be the primary 342 determinant of the flood extent. In most areas, the flood extent 343 that was determined by the SAR will be correct within the SAR 344 resolution, but where errors creep in the lidar can help to correct 345 these.

346 The lidar DTM is able to provide a ground height at each 347 pixel, so that each position $\boldsymbol{u}(x, y)$ becomes $\boldsymbol{u}(x, y, z)$. The 348 modification involves using the lidar heights to measure curva349 tures and tensions at snake nodes in 3-D rather than 2-D space. 350 Consider an instance where an unflooded field with low SAR 351 backscatter is adjacent to a flood edge, such that the field is 352 included in the SAR waterline determined by the snake (Fig. 6). 353 As there will likely be a rise in height $(d h)$ across the field 354 that is perpendicular to the true flood edge, the error in the 355 waterline will give rise to a significant component of curvature 356 in the vertical plane, which will not be present in the waterline 357 segments that are adjacent to the field. To be specific, in Psnake
NT, the contribution to the 3-D curvature energy at the snake 358 node at $\boldsymbol{u}\left(x_{i}, y_{i}, z_{i}\right)$ from its two adjacent nodes is

$$
\Delta E_{\text {curvature }}=\gamma\left|\boldsymbol{v}_{i+1}-\boldsymbol{v}_{i}\right|^{2} / a_{i}=\left(c_{i x}^{2}+c_{i y}^{2}+c_{i z}^{2}\right) / a_{i}
$$

where

$$
\begin{aligned}
c_{i x}= & \left(x_{i+1}-x_{i}\right) / d_{i+1}-\left(x_{i}-x_{i-1}\right) / d_{i} \\
c_{i y}= & \left(y_{i+1}-y_{i}\right) / d_{i+1}-\left(y_{i}-y_{i-1}\right) / d_{i} \\
c_{i z}= & \left(z_{i+1}-z_{i}\right) / d_{i+1}-\left(z_{i}-z_{i-1}\right) / d_{i} \\
d_{i}= & \left(\left(x_{i}-x_{i-1}\right)^{2}+\left(y_{i}-y_{i-1}\right)^{2}+\left(z_{i}-z_{i-1}\right)^{2}\right)^{0.5} \\
d_{i+1}= & \left(\left(x_{i+1}-x_{i}\right)^{2}+\left(y_{i+1}-y_{i}\right)^{2}+\left(z_{i+1}-z_{i}\right)^{2}\right)^{0.5} \\
a_{i}= & \left(\left(\left(x_{i+1}+x_{i}\right) / 2-\left(x_{i}+x_{i-1}\right) / 2\right)^{2}\right. \\
& \quad+\left(\left(y_{i+1}+y_{i}\right) / 2-\left(y_{i}+y_{i-1}\right) / 2\right)^{2} \\
& \left.\quad+\left(\left(z_{i+1}+z_{i}\right) / 2-\left(z_{i}+z_{i-1}\right) / 2\right)^{2}\right)^{0.5}
\end{aligned}
$$

and the suffixes refer to the node numbers in Fig. 6. To reduce 361 the vertical curvature component $c_{i z}^{2}$ at node $i$ in Fig. 6, the 362 snake will try to contract to drag node $i$ back to be collinear 363 with nodes $i-1$ and $i+1$, which will also reduce $c_{i x}^{2}$ and $c_{i y}^{2} .364$ The 3-D tension energy, which is proportional to $\left(d_{i+1}^{2}+d_{i}^{2}\right), 365$ will also be reduced by this move.

A waterline error due to the presence of emergent vegetation 367 at the edge of the flood might also have significant components 368 of vertical curvature and tension that could be reduced by 369 correcting the error. A complicating factor in this case is that 370 the SAR and lidar forces might be acting against each other. In 371 order to reduce the vertical curvature and tension by incorporat- 372 ing the area of enhanced backscatter into the flooded area, the 373 inhomogeneity of the SAR returns in the flooded area would 374 generally have to increase. Which force won out in a particular 375 case would depend on their relative strengths. However, this 376 effect is not the dominant source of error [19].

In order to take account of the fact that a change in height at 378 a node should, in general, cause different changes in curvature 379 and tension compared to the same magnitude change of node 380 position in the $x y$ plane, the lidar heights were scaled by 381 weighting factor $w_{l}$ with respect to the $(x, y)$ coordinates. 382

The straightforward approach to combining the SAR and 383 lidar data would be to use the existing algorithm with both 384 data sets and simply calculate 3-D rather than 2-D curvature 385 and tension energies. A possible objection to this might be that, 386 if there were flooded mounds in the floodplain that are not 387 visible to the SAR but visible to the lidar, these might retard 388 the expansion of the snake and distort the eventual waterline. 389 An alternative approach could be to use the algorithm with 390 SAR data and 2-D curvatures and tensions only initially. Then, 391 the snake iterations could continue using SAR and lidar data, 392 and 3-D curvatures and tensions, causing the snake to adjust 393 itself to correct errors where necessary. However, in cases 394 where the waterline was significantly in error, it might be 395 difficult to recover from these errors. For example, if the snake 396 leaked onto higher ground, it might be impeded from returning 397 to the true waterline position by a hollow in the higher ground. 398 In practice, it turns out that the straightforward approach using 399 
400 the existing algorithm and calculating 3-D curvatures and ten401 sions works well enough.

402 The SAR data may have significantly lower resolution than 403 the airborne lidar data, as in the present test data set comprising 404 ERS satellite SAR data. In this case, it may be possible to 405 correct the waterline position to sub-SAR pixel accuracy in a 406 second pass of the algorithm. The idea would be to rescale the 407 SAR image and the snake waterline from the first pass to the 408 higher resolution of the lidar, and to continue iterating to try to 409 move the snake nodes away from the centers of the enlarged 410 SAR pixels to create a waterline varying more smoothly in 411 height along its length. A constraint would be that a node should 412 not be allowed to move outside its enlarged SAR pixel, as no 413 further information could be extracted from the SAR image at 414 this stage.

\section{B. Implementation and Qualitative Assessment of Results}

416 For the first pass of the modified algorithm, the lidar image 417 was degraded to the same pixel size as the SAR image (12.5 m) 418 by averaging the lidar heights within each SAR pixel. The 419 parameter settings for this pass were the same as those for the 420 snake that was conditioned on only the SAR data (other than for $421 k$ and $w_{l}$ ). The initial value of lidar weight factor $w_{l}$ was chosen 422 by experiment to be 0.15 . This took into account the fact that 423 the leakage at Wytham Hill [at point A in Fig. 5(a)] occurs over 424 a distance of about $0.5 \mathrm{~km}$. Curvature at a node is calculated 425 using the two adjacent nodes on either side of the central node, 426 spanning four internode spacings. For an internode spacing of 427 eight pixels, this corresponds to a distance of about $400 \mathrm{~m}$, 428 roughly matching that required. The $w_{l}$ setting also reflected 429 the facts that the lidar heights were expressed in millimeters 430 and that a, for example, 1000-mm rise in the lidar height of the 431 central node should give rise to a significant increase in 3-D 432 curvature. Even though a node can only be moved horizontally 433 by one SAR pixel at each iteration, this still amounts to a 434 horizontal shift of $12.5 \mathrm{~m}$, which is large compared to a $1-\mathrm{m}$ 435 vertical rise.

436 The original snake seed that was used contained only pixels 437 south of the A40 road west of Oxford (Fig. 1), and it was 438 found on the first pass that, with the 3-D curvature constraint, 439 the snake would not expand into the flooded areas north of the 440 embanked road, even though this was, on average, only $1.5 \mathrm{~m}$ 441 higher than the fields surrounding it. In practice, floodwater 442 from the Thames flows under the A40 onto the lower land 443 to the north through culverts that are spaced at about 250-m 444 intervals. To overcome this difficulty, additional snake seed 445 pixels were inserted to the north of the A40, which were 446 then able to expand into the northernmost part of the flooded 447 region. The same snake seed was used for all snakes that 448 were generated, whether they were conditioned using the lidar 449 data or not.

450 The second pass took place at higher resolution, i.e., at the $4512-\mathrm{m}$ pixel spacing of the lidar data. The input to this pass was 452 the snake output from the first pass, with the node coordinates 453 scaled up by 6.25 to match the change in resolution. The 454 SAR image was interpolated from 12.5 to $2 \mathrm{~m}$ using nearest 455 neighbor interpolation. The number of iterations was set to 3 ,

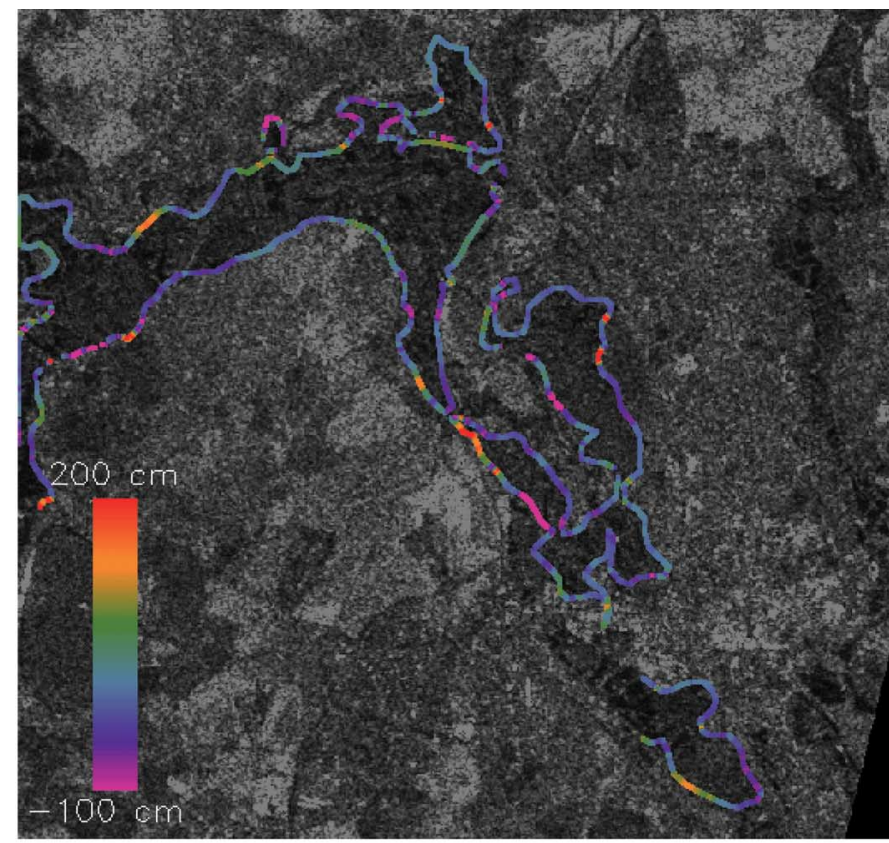

(a)

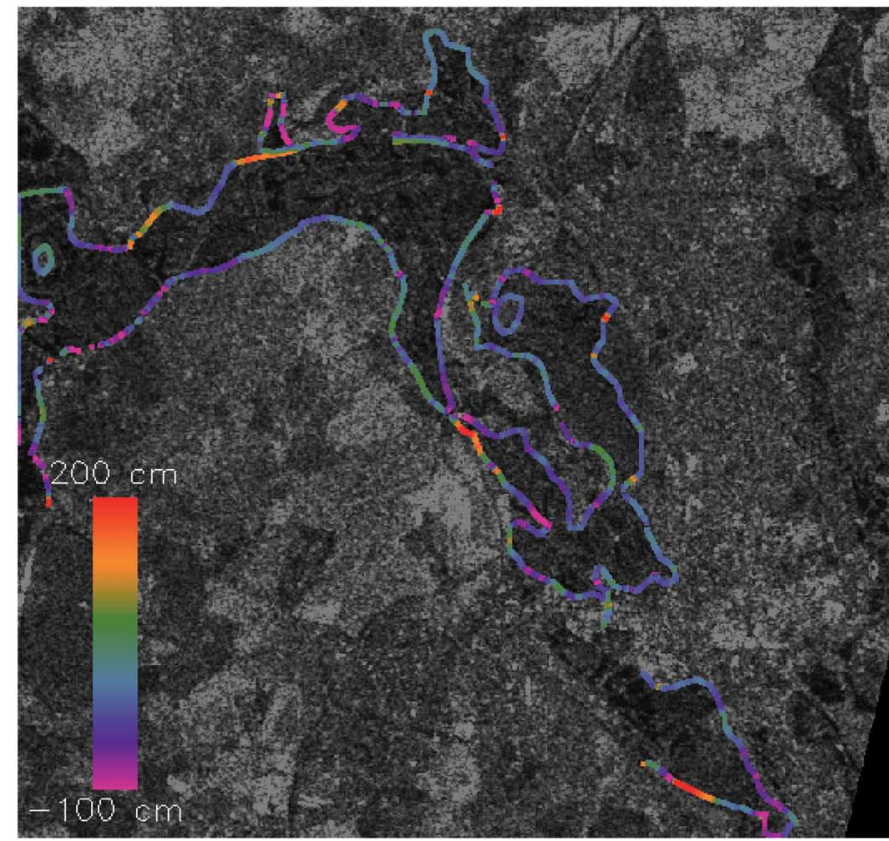

(b)

Fig. 7. Waterline conditioned on SAR and lidar data overlain on SAR data (a) for parameter $k=3$ and $w_{l}=0.15$, and (b) for $k=4$ and $w_{l}=0.15$. The colors represent the difference in height of the waterline from the local mean waterline height.

to ensure that the snake nodes would not move outside the SAR 456 pixels within which they had stabilized after the first pass. The 457 minimum and maximum node spacings were also upscaled to 458 37 and 74 pixels, respectively, ensuring similar 3-D curvatures 459 to those on the first pass.

Fig. 7 shows snake waterlines that were conditioned on both 461 SAR and lidar data, for $k$ values of 3 and 4 and lidar weight 462 $w_{l}=0.15$, overlain on 12.5-m SAR data. It is clear that the 463 tendency for the snake to leak to higher ground at Wytham Hill 464 and at the Oxford Nature Park has been much reduced (see 465 
466 also Fig. 3). A further benefit is that the snake appears to be 467 more stable to parameter changes. For example, in Fig. 5, the 468 snake that was conditioned only on SAR data shows substantial 469 change when $k$ is raised from 2 to 3, whereas in Fig. 7, the snake 470 that was conditioned on SAR and lidar shows less change when $471 k$ is raised from 3 to 4 . This finding is born out more rigorously 472 in the quantitative analysis described in the next section.

473 The main errors in waterline position that were corrected 474 using the lidar data are due to the unflooded short vegetation 475 that is adjacent to the flood giving similar returns to open water. 476 The ability of the algorithm to correct loss of flood extent due to 477 emergent vegetation is hardly tested using this data set, as this 478 has few significant examples. The most obvious instances are 479 emergent hedges between adjacent flooded fields, but these are 480 generally of insufficient area to stop the snake subsuming them 481 into its interior, even if conditioned only on SAR data.

\section{V. PARAMETER Optimization And QuAntitative 483 COMPARISON OF METHODS}

484 The snake parameters were optimized using a quantitative 485 measurement of algorithm performance. The snake and aerial 486 photo waterlines were first heighted by superimposing them 487 on the lidar DTM. The snake waterline is defined only at the 488 snake nodes. Only nodes on low slopes and in areas of short 489 vegetation in the lidar vegetation height map were selected for 490 heighting, as these are the ones that are likely to be heighted 491 most accurately. The lower the slope, the smaller the node 492 height error for a given error in its position. No requirements 493 were made that selected nodes should have a strong SAR edge 494 [indicated by a low $G$ value (2)] associated with them, as this 495 would reject nodes at the boundaries between the flood and 496 an unflooded field giving low SAR backscatter, or between a 497 region of emergent vegetation at the flood edge and an adjacent 498 unflooded land (both giving high SAR backscatter).

499 For each snake node that was selected, the aerial photo height 500 to associate with the snake height was found by finding the 501 height of the closest aerial photograph waterline point. This 502 was found by applying a distance-with-destination transform to 503 the aerial photo waterline image. The distance-with-destination 504 transform is a form of distance transform that stores, for each 505 pixel in the transform image, its distance to the nearest wa506 terline point and also the direction from which the minimum 507 distance was propagated. This allows backtracking from a 508 pixel to find its nearest waterline point [31]. Corroborating the 509 finding of [19], the average separation distance was about $50 \mathrm{~m}$, 510 although this value was strongly influenced by a small number 511 of pairs having large separations, and the average separation 512 of $70 \%$ of the pairs having separations of less than $50 \mathrm{~m}$ 513 was only $20 \mathrm{~m}$. However, the pairs with large separation were 514 not rejected, as they included examples where, e.g., the SAR 515 waterline was displaced from the aerial photo waterline by a 516 complete field width due to misclassification of the field as 517 flooded. The anticipation was that these events would be less 518 common when the snake was conditioned on the SAR and lidar 519 data than on the SAR data alone.

520 Parameters were optimized by minimizing the sum of the 521 squared height differences between the snake nodes and their corresponding aerial photo waterline points. To ensure that 522 adjacent pairs of heights were largely uncorrelated, the pairs 523 that were selected so far were thinned further, so that no 524 pair was closer than $200 \mathrm{~m}$ to another. This distance was 525 estimated by constructing a correlogram from the set of pairs 526 [32] and was the distance at which the average correlation 527 between adjacent pairs became less than 0.2. From the remain- 528 ing pairs, the mean and standard deviations of the snake and 529 aerial photograph waterline heights were calculated, as was 530 the rms error of the height differences, with this being the 531 variable to minimize in the parameter optimization. The mean 532 height difference and the standard deviation of the differences 533 were also calculated, and this allowed a paired t-test to be 534 performed to test whether the differences were significantly 535 nonzero. The paired t-test is used to exploit the fact that, while 536 corresponding SAR and aerial photograph waterline heights 537 will be correlated due to the gradual drop in height along the 538 reach, the height differences at corresponding nodes will be 539 uncorrelated due to the thinning process, as required by the 540 paired test.

541

Only the most important parameters were investigated in the 542 optimization procedure. For the snake that was conditioned 543 on only SAR data, the parameter that was optimized was $k .544$ For the snake that was conditioned on SAR and lidar data, $k 545$ and $w_{l}$ were optimized.

546

Table I(a) shows the results of varying $k$ for the snake that 547 was conditioned on only the SAR data. The minimum rms error 548 is $221.1 \mathrm{~cm}$, which was obtained for $k=2.0$. The associated 549 high $t$ value implies that there is a significant height difference 550 at the $5 \%$ level between the snake and aerial photo waterlines. 551 The corresponding snake is shown in Fig. 5(b). Higher values 552 of $k$ give significantly larger rms errors, and the high $t$ values 553 that were coupled with positive mean height differences imply 554 that, for all these $k$ values, the snake waterline heights are 555 significantly higher than those of the aerial photograph. 556

Table I(b) shows the results of varying $k$ for the snake that 557 was conditioned on SAR and lidar data, with $w_{l}$ held constant 558 at 0.15 . The minimum rms error is $55.5 \mathrm{~cm}$, which was obtained 559 for $k=3.0$. The associated $t$ value is not significantly nonzero, 560 so that there is no significant difference between the snake 561 and aerial photo waterline heights. The corresponding snake is 562 shown in Fig. 7(a).

Table I(c) shows the results of varying $w_{l}$ for the snake that 564 was conditioned on SAR and lidar data, with $k$ held constant 565 at 3.0. The minimum rms error is obtained at $w_{l}=0.15$. Over 566 the ranges of $k$ and $w_{l}$ that were investigated, none of the $t 567$ values are significantly nonzero, implying greater robustness 568 to parameter changes than the case for the snake that was 569 conditioned on only SAR data.

Table II gives the frequency tables of the absolute differences 571 of the paired heights for the parameter sets giving the minimum 572 rms errors for the snake that was conditioned on only the SAR 573 data and the snake that was conditioned on SAR and lidar data. 574 It can be seen that the increase in the rms error in the case of 575 the snake that was conditioned only on SAR data is due almost 576 entirely to the large number of pairs having height differences 577 of greater than $300 \mathrm{~cm}$. This is also apparent in Fig. 8, where 578 the paired height differences for the two cases are plotted as a 579 
TABLE I

RESUltS OF (a) VARYING $k$ FOR THE SNAKE CONDITIONED ON ONLY THE SAR DATA, (b) VARYING $k$ FOR THE SNAKE CONDITIONED ON SAR AND LidAR DATA, WITH $w_{l}$ HELd CONSTANT AT 0.15, AND (c) VARYING $w_{l}$ FOR THE SNAKE CONDITIONED ON SAR AND LIDAR DATA, With $k$ HELD CONSTANT AT 3.0

\begin{tabular}{|c|c|c|c|c|c|c|}
\hline$k$ & $\begin{array}{c}\text { Number of } \\
\text { height } \\
\text { pairs }\end{array}$ & $\begin{array}{c}\text { R.m.s. } \\
\text { error in } \\
\text { height } \\
(\mathrm{cm})\end{array}$ & $\begin{array}{c}\text { Mean } \\
\text { height } \\
\text { difference } \\
(\mathrm{cm})\end{array}$ & $t_{0}$ & $\begin{array}{c}\text { Probability } \\
t>\left|t_{0}\right| \\
\text { (one-sided } \\
\text { test) }\end{array}$ & $\begin{array}{c}\text { Relative } \\
\text { height } \\
\text { standard } \\
\text { deviation } \\
(\mathrm{cm})\end{array}$ \\
\hline 1.5 & 165 & 238.8 & 31.6 & 1.7 & 0.04 & 105.3 \\
\hline 2.0 & 200 & 221.1 & 33.7 & 2.2 & 0.02 & 136.2 \\
\hline 2.5 & 197 & 381.3 & 65.4 & 2.4 & 0.01 & 263.1 \\
\hline 3.0 & 195 & 331.4 & 64.5 & 2.8 & 0.004 & 314.4 \\
\hline 4.0 & 206 & 317.5 & 70.7 & 3.3 & 0.0005 & 379.1 \\
\hline
\end{tabular}

(a)

\begin{tabular}{|c|c|c|c|c|c|c|}
\hline$k$ & $\begin{array}{c}\text { Number of } \\
\text { height } \\
\text { pairs }\end{array}$ & $\begin{array}{c}\text { R.m.s. } \\
\text { error in } \\
\text { height } \\
(\mathrm{cm})\end{array}$ & $\begin{array}{c}\text { Mean } \\
\text { height } \\
\text { difference } \\
\text { (cm) }\end{array}$ & $t_{0}$ & $\begin{array}{c}\text { Probability } \\
t>\left|t_{0}\right|\end{array}$ & $\begin{array}{c}\text { Relative } \\
\text { height } \\
\text { standard } \\
\text { deviation } \\
\text { (cm) }\end{array}$ \\
\hline 2.8 & 195 & 57.8 & -1.5 & -0.4 & 0.35 & 43.5 \\
\hline 3.0 & 191 & 55.5 & -4.3 & -1.0 & 0.15 & 42.6 \\
\hline 3.2 & 190 & 86.6 & -3.1 & -0.5 & 0.30 & 52.6 \\
\hline 3.5 & 195 & 120.8 & 5.2 & 0.6 & 0.28 & 65.4 \\
\hline 4.0 & 195 & 63.7 & 4.5 & 1.0 & 0.15 & 48.9 \\
\hline
\end{tabular}

(b)

\begin{tabular}{|c|c|c|c|c|c|c|}
\hline$w_{l}$ & $\begin{array}{c}\text { Number of } \\
\text { height } \\
\text { pairs }\end{array}$ & $\begin{array}{c}\text { R.m.s. } \\
\text { error in } \\
\text { height } \\
(\mathrm{cm})\end{array}$ & $\begin{array}{c}\text { Mean } \\
\text { height } \\
\text { difference } \\
(\mathrm{cm})\end{array}$ & $t_{0}$ & $\begin{array}{c}\text { Probability } \\
t>\left|t_{0}\right|\end{array}$ & $\begin{array}{c}\text { Relative } \\
\text { height } \\
\text { standard } \\
\text { deviation } \\
(\mathrm{cm})\end{array}$ \\
\hline 0.10 & 187 & 90.2 & -0.1 & -0.1 & 0.46 & 47.4 \\
\hline 0.14 & 196 & 61.0 & 5.4 & 1.2 & 0.10 & 43.0 \\
\hline 0.15 & 191 & 55.5 & -4.3 & -1.0 & 0.15 & 42.6 \\
\hline 0.16 & 191 & 55.8 & 0.7 & 0.2 & 0.42 & 43.5 \\
\hline 0.20 & 195 & 81.5 & -9.0 & -1.5 & 0.07 & 54.7 \\
\hline
\end{tabular}

(c)

580 function of distance downstream. The main effect of the lidar 581 data is to correct errors in the sections of waterline containing 582 these outliers, when the snake is conditioned on both SAR and 583 lidar.

584 The effect of the second pass of the algorithm in correcting 585 the waterline position to sub-SAR pixel accuracy was also 586 assessed. For the parameter set giving the minimum rms error 587 for the snake that was conditioned on SAR and lidar data $588\left(k=3.0\right.$ and $\left.w_{l}=0.15\right)$, the algorithm was run for only the 589 first pass. The minimum rms error was $58.1 \mathrm{~cm}$, which is 590 only slightly higher than the $55.5 \mathrm{~cm}$ that was achieved when 591 both passes were employed. There was slightly more difference 592 when $k$ was raised to 4.0 and when the rms error increased to 59370.8 from 63.7. This indicates that the main reduction in error is 594 being generated in the first pass and that the second gives only 595 a second-order improvement. This may be partly because only 596 snake nodes on low slopes have been selected, and thus, height 597 differences across the SAR pixel, due to its size, will be small.
TABLE II

Frequency TABles of the ABSOLUte DifFerences of PAired Heights for the Parameter Sets Giving the Minimum RMS ERRORS FOR THE SNAKE CONDITIONED ON ONLY THE SAR DATA AND THE SNAKE CONDITIONED ON SAR AND LIDAR DATA

\begin{tabular}{|l|c|c|c|c|c|c|c|c|}
\hline & $\begin{array}{c}0- \\
49 \mathrm{~cm}\end{array}$ & $\begin{array}{c}50- \\
99 \mathrm{~cm}\end{array}$ & $\begin{array}{c}100- \\
149 \mathrm{~cm}\end{array}$ & $\begin{array}{c}150- \\
199 \mathrm{~cm}\end{array}$ & $\begin{array}{c}200- \\
249 \mathrm{~cm}\end{array}$ & $\begin{array}{c}250- \\
299 \mathrm{~cm}\end{array}$ & $\begin{array}{c}300- \\
499 \mathrm{~cm}\end{array}$ & $>=500 \mathrm{~cm}$ \\
\hline $\begin{array}{l}\text { Snake } \\
\text { conditioned } \\
\text { on SAR data } \\
(k=2.0)\end{array}$ & 155 & 20 & 9 & 3 & 3 & 1 & 3 & 6 \\
\hline $\begin{array}{l}\text { Snake } \\
\text { conditioned } \\
\text { on SAR and } \\
\begin{array}{l}\text { LiDAR data } \\
\left(k=3.0, w_{l}=\right. \\
0.15)\end{array}\end{array}$ & 154 & 20 & 9 & 5 & 2 & 1 & 0 & 0 \\
\hline
\end{tabular}

VI. DISCUSSION

The method may be applied to the validation of the flood 599 models of other river reaches, with the only prerequisites 600 additional to the usual data required to set up a hydraulic 601 model (e.g., an inflow hydrograph and river channel cross- 602 sectional data) being the availability of SAR imagery of the 603 river in flood and reasonably contemporaneous lidar data of 604 the unflooded reach. It would be relatively straightforward to 605 make the procedure operational. Lidar data are now often used 606 to parameterize the hydraulic model, making it more likely that 607 they would also be available to improve the SAR waterline. 608 It would be straightforward to implement the modified algo- 609 rithm within the Psnake NT software package. For this catch- 610 ment, the algorithm processing time was less than 1 min on a 611 Pentium IV personal computer.

The emphasis in the foregoing has been on ERS satellite 613 SAR data because of the availability of simultaneous ERS SAR 614 and aerial photography of the 1992 Oxford flood. While ERS 615 SAR data have poorer resolution than airborne lidar data, the 616 technique should also be applicable in cases where the SAR 617 resolution is similar to that of the lidar (e.g., airborne SAR), 618 in which case a second pass of the algorithm would certainly 619 be unnecessary. The algorithm of [18] and [19] has been used 620 to delineate flood extents in airborne SAR imagery [33], [34]. 621 However, given the increasing number of satellite SAR sensors 622 flying or planned and the difficulty of flying aircraft in poor 623 weather often accompanying floods, satellite SARs are likely 624 to remain to be a major source of SAR data for flood mapping 625 in the future. While the ERS SAR sensor has single VV polar- 626 ization and a fixed $23^{\circ}$ viewing angle, the advent of later sensors 627 with higher resolutions, multiple polarizations, and variable 628 viewing angles (e.g., RADARSAT and Envisat Advanced SAR) 629 has allowed improved flood delineation (e.g., [15]). The high- 630 resolution satellite SAR sensors due for launch shortly (e.g., 631 RADARSAT-2, TerraSAR, and the Cosmo-Skymed constella- 632 tion) will have resolutions that match or almost match that of 633 airborne lidar.

Production of a more smoothly varying waterline may allow 635 the development of improved performance measures for flood 636 extent validation based on patterns of height differences be- 637 tween observed and modeled waterlines rather than on patterns 638 of wet or dry pixels, as currently done. Aronica et al. [24] 639 


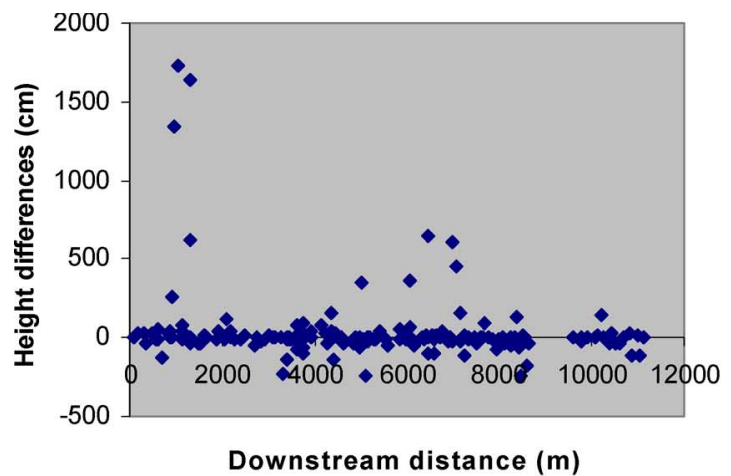

(a)

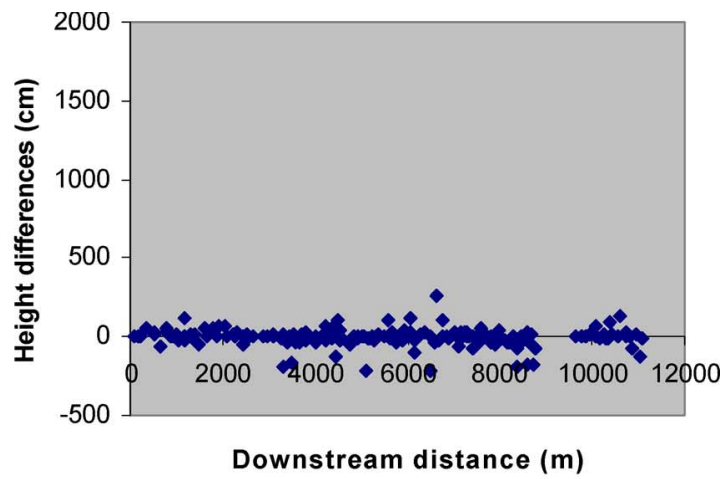

(b)

Fig. 8. Paired height differences versus distance downstream for the parameter sets giving the minimum rms errors for the snake that was conditioned on (a) SAR data and (b) SAR and lidar data.

640 describe current performance measures based on binary pat641 terns. One measure representative of these is

$$
F^{(2)}=\left(A_{\text {obs }} \bigcap A_{\text {mod }}\right) /\left(A_{\text {obs }} \bigcup A_{\text {mod }}\right)
$$

642 where $A_{\text {obs }}$ and $A_{\text {mod }}$ represent the set of pixels that are ob643 served to be inundated and predicted as inundated, respectively. $644 F^{(2)}$ is equal to 1 when observed and predicted areas coincide 645 exactly and equal to 0 when no overlap between predicted and 646 observed areas exists. A performance measure based on height 647 differences might have several advantages over one such as $648 F^{(2)}$ based on binary pattern data. First, as the distribution of $649 t$ is known, it is possible to estimate the probability $P\left(t>\left|t_{0}\right|\right)$ 650 of obtaining a $t$ value that is greater than the absolute value 651 of that measured $\left(t_{0}\right)$, whereas $F^{(2)}$ is simply a weight factor. 652 Second, the height difference measure between two model 653 runs with different parameter settings might turn out to be 654 more sensitive than $F^{(2)}$, because a small change in mean 655 height might cause a large change in $P\left(t>\left|t_{0}\right|\right)$ yet only a 656 small change in $F^{(2)}$. Third, the sign of the $t$ value identifies 657 whether an overprediction or an underprediction has occurred, 658 whereas $F^{(2)}$ may give similar values for overprediction and 659 underprediction.

660 In this case, the parameters of the snake that was generated 661 using SAR and lidar have been optimized using the aerial 662 photo waterline, but this will not be available in the more usual 663 situation in which the snake is being used to validate a model 664 waterline. It is interesting that, for those nodes in areas of low 665 slope and low vegetation, the standard deviation of their heights 666 relative to their local mean height (within an $0.5-\mathrm{km}$ distance) 667 is a minimum at the same parameter setting at which the rms 668 error of height differences between snake and aerial photo 669 waterlines is minimized [Table I(b) and (c)]. This presumably 670 reflects the fact that the snake is most smoothly varying when 671 the relative height standard deviation is minimized, and it may 672 be possible to use this measure as a surrogate for optimizing the 673 snake parameters when using the snake to validate a modeled 674 flood extent. However, a more likely scenario is that a single 675 optimum parameter set would not be sought in this situation. In 676 flood model validation, emphasis is now placed on associating 677 uncertainties with model flood extents, by deriving flood extent probability maps showing the probability of each pixel being 678 flooded, given a flood event of the given magnitude. It has 679 been found that, for a particular event, many different sets 680 of model parameters may give flood extents that match the 681 observed extent to a greater or lesser degree. Such equifinality 682 has been well documented and has resulted in the development 683 of the generalized likelihood uncertainty estimation (GLUE) 684 technique, whereby many model runs are carried out, spanning 685 the likely ranges of model parameters [35]. A flood extent 686 probability map is obtained by performing a weighted average 687 of the binary-valued modeled flood extents (with the value for 688 a pixel being 1 for flooded and 0 for not flooded), with each 689 model flood extent being weighted according to its performance 690 measure relative to an observed flood extent. As previously 691 mentioned, the performance measure could be based on pat- 692 terns of height differences between observed and modeled 693 waterlines rather than on patterns of wet or dry pixels. To date, 694 the GLUE methodology has been mainly used to assess flood 695 extent uncertainty due to model parameter errors (see, e.g., [21] 696 and [36]). However, it seems a natural future step to try to 697 extend the method to cope with uncertainty in both model and 698 snake algorithm parameters [36]. Some method of limiting the 699 number of model runs that are required would probably need to 700 be employed (e.g., Gaussian emulation [37]), although some 701 reduction might result from using an improved performance 702 measure based on height differences.

\section{CONCLUSION}

An algorithm has been developed for the automatic 705 extraction of flood extent using a snake that was generated 706 from combined SAR and lidar data, and the resulting waterline 707 compared to that generated using SAR data alone. From the re- 708 sulting snakes, sets of nodes in areas of low slope and low veg- 709 etation have been extracted, followed by further thinning. After 710 optimization of parameters, the heights of the resulting node set 711 from the snake that was conditioned on SAR and lidar matched 712 the corresponding node heights from the aerial photo waterline 713 significantly more closely than those from the snake that was 714 conditioned solely on SAR data. The conclusion is that, for 715 the variety of situations that are present in this particular 716 
717 data set, the use of the lidar data has resulted in an observed 718 waterline that varies more smoothly along the reach and is a 719 better match to our best estimate of the true waterline heights.

\section{ACKNOWLEDGMENT}

721 The authors would like to thank the EA for the provision 722 of lidar data, CEH Wallingford for the SAR and photographic 723 data, and the referees for their improvements to this paper.

724

725

\section{REFERENCES}

[1] P. D. Bates, M. S. Horritt, C. N. Smith, and D. C. Mason, "Integrating remote sensing observations of flood hydrology and hydraulic modeling," Hydrol. Process., vol. 11, no. 14, pp. 1777-1795, 1997.

[2] L. C. Smith, "Satellite remote sensing of river inundation area, stage and discharge: A review," Hydrol. Process., vol. 11, no. 10, pp. 14271439, 1997.

[3] F. T. Ulaby, R. K. Moore, and A. K. Fung, Microwave Remote Sensing, vol. 3. Norwood, MA: Artech House, 1986.

4] J.-S. Lee and I. Jurkevich, "Coastline detection and tracing in SAR images," IEEE Trans. Geosci. Remote Sens., vol. 28, no. 4, pp. 662-668, Jul. 1990.

[5] D. C. Mason and I. J. Davenport, "Accurate and efficient determination of the shoreline in ERS-1 SAR images," IEEE Trans. Geosci. Remote Sens., vol. 34, no. 5, pp. 1243-1253, Sep. 1996.

[6] J. A. Richards, P. W. Woodgate, and A. K. Skidmore, "An explanation of enhanced radar backscattering from flooded forests," Int. J. Remote Sens., vol. 8, no. 7, pp. 1093-1100, 1987.

[7] F. M. Henderson, "Environmental factors and the detection of open surface water using X-band radar imagery," Int. J. Remote Sens., vol. 16, no. 13, pp. 2423-2437, 1995.

[8] S. I. Solomon, "Methodological considerations for the use of ERS-1 SAR imagery for the delineation of river networks in tropical forest areas," in Proc. 1st ERS-1 Symp., Frascati, Italy, Jun. 26-27, 1995, pp. 595-600.

[9] M. S. Horritt, D. C. Mason, D. M. Cobby, I. J. Davenport, and P. D. Bates, "Waterline mapping in flooded vegetation from airborne SAR imagery," Remote Sens. Environ., vol. 85, no. 3, pp. 271-281, May 2003.

10] Y. Wang, L. L. Hess, S. Filoso, and J. M. Melack, "Understanding the radar backscattering from flooded and non-flooded Amazonian forests: Results from canopy backscatter modelling," Remote Sens. Environ., vol. 54, no. 3, pp. 324-332, Dec. 1995.

1] M. Badji and S. Dautrebande, "Characterisation of flood inundated areas and delineation of poor drainage soil using ERS-1 SAR imagery," Hydrol. Process., vol. 11, no. 10, pp. 1441-1450, 1995.

12] M. L. Imhoff, C. Vermillion, M. H. Story, A. M. Choudhury, A. Gafoor, and F. Poclyn, "Monsoon flood boundary delineation and damage assessment using space borne imaging radar and Landsat data," Photogramm. Eng. Remote Sens., vol. 53, no. 4, pp. 405-413, 1987.

13] H. Liu and K. C. Jezek, "Automated extraction of coastline from satellite imagery by integrating Canny edge detection and locally adaptive thresholding method," Int. J. Remote Sens., vol. 25, no. 5, pp. 937-958, 2004.

4] A. Niedermeier, E. Romaneessen, and S. Lehner, "Detection of coastlines in SAR images using wavelet methods," IEEE Trans. Geosci. Remote Sens., vol. 38, no. 5, pp. 2270-2281, Sep. 2000.

5] Y. Yu and S. T. Acton, "Automated delineation of coastline from polarimetric SAR imagery," Int. J. Remote Sens., vol. 25, no. 17, pp. 3423-3438, Sep. 2004.

16] P. A. Brivio, R. Colombo, M. Maggi, and R. Tomasoni, "Integration of remote sensing data and GIS for accurate mapping of flooded areas," Int. J. Remote Sens., vol. 23, no. 3, pp. 429-441, Feb. 2002.

17] G. Nico, M. Pappalepore, G. Pasquariello, A. Refice, and S. Samarelli, "Comparison of SAR amplitude vs. coherence flood detection methods-A GIS application," Int. J. Remote Sens., vol. 21, no. 8, pp. 1619-1631, May 2000.

$18]$ M. S. Horritt, "A statistical active contour model for SAR image segmentation," Image Vis. Comput., vol. 17, no. 3/4, pp. 213-224, Mar. 1999.

19] M. S. Horritt, D. C. Mason, and A. J. Luckman, "Flood boundary delineation from synthetic aperture radar imagery using a statistical active contour model," Int. J. Remote Sens., vol. 22, no. 13, pp. 2489-2507, Sep. 2001.

20] G. Schumann, R. Hostache, C. Puech, L. Hoffmann, P. Matgen, F. Pappenberger, and L. Pfister, "High-resolution 3D flood information from radar imagery for flood hazard management," IEEE Trans. Geosci. 786 Remote Sens., vol. 45, no. 6, pp. 1715-1725, Jun. 2007.

[21] F. Pappenberger, K. Beven, M. Horritt, and S. Blazkova, "Uncertainty in 788 the calibration of effective roughness parameters in HEC-RAS using inun- 789 dation and downstream level observations," J. Hydrol., vol. 302, no. 1-4, 790 pp. 46-69, 2005.

[22] D. C. Mason, D. M. Cobby, M. S. Horritt, and P. D. Bates, "Flood- 792 plain friction parameterization in two-dimensional river flood models 793 using vegetation heights derived from airborne scanning laser altimetry," 794 Hydrol. Process., vol. 17, no. 9, pp. 1711-1732, 2003.

[23] D. M. Cobby, D. C. Mason, M. S. Horritt, and P. D. Bates, "Two- 796 dimensional hydraulic flood modelling using a finite element mesh de- 797 composed according to vegetation and topographic features derived from 798 airborne scanning laser altimetry," Hydrol. Process., vol. 17, no. 10, 799 pp. 1979-2000, 2003.

[24] G. Aronica, P. D. Bates, and M. S. Horritt, "Assessing the uncertainty in 801 distributed model predictions using observed binary pattern information 802 within GLUE," Hydrol. Process., vol. 16, no. 10, pp. 2001-2016, 2002.803

[25] D. S. Biggin and K. Blyth, "A comparison of ERS-1 satellite radar and 804 aerial photography for river flood mapping," J. Chart. Inst. Water Eng. 805 Manag., vol. 10, pp. 1777-1795, 1996.

[26] L. M. G. Pereira and L. L. F. Janssen, "Suitability of laser data for DEM 807 generation: A case study in the context of road planning and design," 808 ISPRS J. Photogramm. Remote Sens., vol. 54, no. 4, pp. 244-253, 1999.809

[27] I. J. Davenport, N. Holden, and R. J. Gurney, "Characterizing errors 810 in airborne laser altimetry data to extract soil roughness," IEEE Trans. 811 Geosci. Remote Sens., vol. 42, no. 10, pp. 2130-2141, Oct. 2004.

[28] D. J. Williams and M. Shah, "A fast algorithm for active contours and 813 curvature estimation," CVGIP, Image Underst., vol. 55, no. 1, pp. 14-26, 814 Jan. 1992.

[29] J. Ivins and J. Porrill, "Statistical snakes: Active region models," in 816 Proc. 5th Brit. Mach. Vis. Conf., York, U.K., Sep. 1994, vol. 1 and 2, 817 pp. 377-386.

[30] M. S. Horritt, "Psnake NT user manual," Univ. Bristol, Bristol, U.K., 819 2002. School of Geographical Sciences Report.

[31] D. C. Mason, T. R. Scott, and H.-J. Wang, "Extraction of tidal channel 821 networks from airborne lidar data," ISPRS J. Photogramm. Remote Sens., 822 vol. 61, no. 2, pp. 67-83, 2006.

[32] C. V. Deutsch and A. Journel, GSLIB: Geostatistical Software Library and 824 Users's Guide. New York: Oxford Univ. Press, 1992, p. 41.

[33] P. D. Bates, M. Wilson, M. S. Horritt, D. C. Mason, N. Holden, and 826 A. Currie, "Reach scale floodplain inundation dynamics observed using 827 airborne SAR imagery," J. Hydrol., vol. 328, no. 1/2, pp. 306-318, 2006. 828

[34] S. Neelz, G. Pender, I. Villanueva, M. D. Wilson, N. G. Wright, 829 P. D. Bates, D. C. Mason, and C. Witlow, "Using remotely sensed 830 data to support flood modelling," Proc. Inst. Civil Eng., vol. 159, no. 1, 831 pp. 35-44, 2006.

[35] K. J. Beven and A. M. Binley, "The future of distributed models: Model 833 calibration and predictive uncertainty," Hydrol. Process., vol. 6, no. 3, 834 pp. 279-298, 1992.

[36] M. S. Horritt, "A methodology for the validation of uncertain flood inun- 836 dation models," J. Hydrol., vol. 326, no. 1-4, pp. 153-165, 2006.

[37] J. E. Oakley and A. O'Hagan, "Probabilistic sensitivity analysis of com- 838 plex models: A Bayesian approach," J. R. Stat. Soc., Series B, vol. 66, 839 no. 3, pp. 751-769, Aug. 2004.

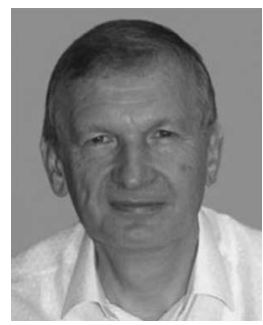

David C. Mason received the B.Sc. and Ph.D. de- 841 grees in physics from the University of London, 842 London, U.K., in 1963 and 1968, respectively. 843

He was with the U.K. Medical Research Coun- 844 cil and Plessey Electronic Systems Research. Since 845 1984, he has been with the Natural Environment 846 Research Council Environmental Systems Science 847 Centre, University of Reading, Reading, U.K., carry- 848 ing out research on the automated extraction of infor- 849 mation from remotely sensed data and linking these 850 data to environmental models. His current research 851 interests include using remotely sensed data for validation and parameterization 852 of river flood models and assimilation into coastal morphodynamic models. 853 


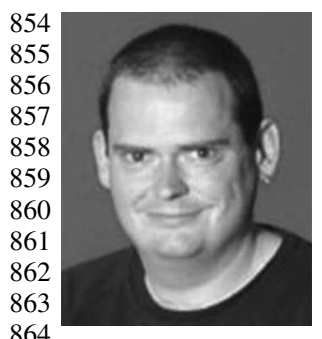

Matthew S. Horritt received the Ph.D. degree from the University of Reading, Reading, U.K., in 1998.

He was with the University of Leeds, Leeds, U.K., and the Department of Civil Engineering, University of Bristol, Bristol, U.K., as a Postdoctoral Research Fellow and a Lecturer in civil engineering, respectively. $\mathrm{He}$ is currently a Specialist Modeler with Halcrow Group Ltd., London, U.K. His research interests are flood inundation models, remote sensing of floods and floodplain topography, and model validation.

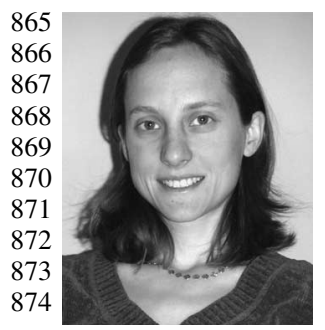

Johanna T. Dall'Amico is currently working toward the B.Sc. degree in mathematics at the University of Reading, Reading, U.K., and a Diploma in geography and remote sensing at Ludwig-Maximilian University of Munich, Munich, Germany.

She is a Visiting Student at the Natural Environment Research Council Environmental Systems Science Centre, University of Reading, where she works on remote sensing applications for fluvial flood models.

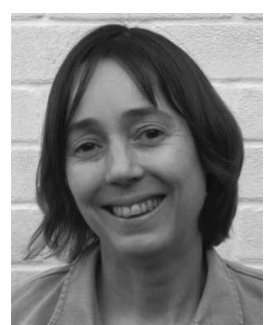

Tania R. Scott received the B.Sc. degree in 875 astronomy from the University of Canterbury, 876 Christchurch, New Zealand, in 1992 and the 877 $\mathrm{Ph}$.D. degree in astronomy from the University of 878 Cambridge, Cambridge, U.K., in 1998.

She was with the U.K. Met Office, where she 880 developed meteorological products for the aviation 881 industry to address safety and environmental issues. 882 She is currently with the Natural Environment 883 Research Council (NERC) Environmental Systems 884 Science Centre, University of Reading, Reading, 885 U.K., where she is interested in using remote sensing data in aid of environ- 886 mental modeling. Her current project is to apply data assimilation techniques 887 to coastal area morphodynamic modeling, which is funded under the NERC 888 program Flood Risk from Extreme Events.

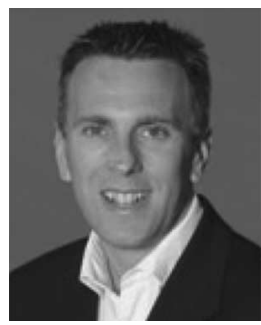

Paul D. Bates received the Ph.D. degree from the 890 University of Bristol, Bristol, U.K., in 1993, with 891 support from a Natural Environmental Research 892 Council studentship.

Subsequently, he has been with at the Univer- 894 sity of Bristol as a Postdoctoral Researcher and 895 Lecturer, and has been a Full Professor since 896 2003. He is currently the Director of the Hydrology 897 Research Group, School of Geographical Sciences, 898 University of Bristol. He has been a Visiting Sci- 899 entist at Princeton University, Laboratoire National 900 D'Hydraulique, Paris, and the EU Joint Research Centre, Ispra, Italy. His 901 research interests include the development and analysis of numerical models for 902 predicting river flood flows, principally using data derived from remote sensing 903 sources, spatial prediction, risk, and uncertainty. He is the Editor-in-Chief of 904 the International Journal of River Basin Management. 


\author{
David C. Mason, Matthew S. Horritt, Johanna T. Dall'Amico, Tania R. Scott, and Paul D. Bates
}

\begin{abstract}
5 Abstract-Flood extent maps that are derived from synthetic 6 aperture radar (SAR) images provide spatially distributed data 7 for validating hydraulic models of river flood flow. The accuracy of 8 such maps is reduced by a number of factors, including variation 9 in backscatter from the different land cover types that are adjacent 10 to the flood, changes in returns from the water surface that are 11 caused by different meteorological conditions, and the presence of 12 emergent vegetation. This paper describes how improved accuracy 13 can be achieved by modifying an existing flood extent delineation 14 algorithm to use airborne laser altimetry [light detection and 15 ranging (lidar)] as well as SAR data. The lidar data provide an 16 additional constraint that waterline heights should vary smoothly 17 along the flooded reach. The method was tested on a SAR image 18 of a flood for which contemporaneous aerial photography existed, 19 together with lidar data of the unflooded reach. The waterline 20 heights of the SAR flood extent that was conditioned on both SAR 21 and lidar data matched the corresponding heights from the aerial 22 photograph waterline significantly more closely than those from 23 the SAR flood extent that was conditioned only on SAR data. 24 For waterline heights in areas of low slope and vegetation, the 25 root-mean-square error on the height differences reduced from $26 \mathbf{2 2 1 . 1} \mathrm{cm}$ for the latter case to $\mathbf{5 5 . 5} \mathrm{cm}$ for the former.
\end{abstract}

Index Terms-Data fusion, hydrology, lidar, snake.

\section{INTRODUCTION}

29 LOOD extent maps that are derived from remotely sensed 30 data are of considerable use in hydrology, providing spa31 tially distributed data for validation of hydraulic models of river 32 flood flow, for emergency flood relief management, and for 33 development of spatially accurate hazard maps [1], [2]. The all34 weather day-night capability of synthetic aperture radar (SAR) 35 sensors gives these a considerable advantage for flood mapping 36 over sensors operating at visible or infrared wavelengths, as the 37 latter ones are unable to penetrate the cloud that often accom38 panies flood events. This advantage is tempered by the fact that 39 a number of factors conspire to reduce the accuracy of flood 40 maps that are derived from SAR imagery. These include the

Manuscript received October 9, 2006; revised March 26, 2007. This work was supported in part by the EPSRC-funded Flood Risk Management Research Consortium Grant GR/S76394/01.

D. C. Mason, J. T. Dall'Amico, and T. R. Scott are with the Natural Environment Research Council Environmental Systems Science Centre, University of Reading, RG6 6AH Reading, U.K.

M. S. Horritt is with Halcrow Group Ltd., W6 7BY London, U.K

P. D. Bates is with the School of Geographical Sciences, University of Bristol, BS8 1SS Bristol, U.K.

Color versions of one or more of the figures in this paper are available online at http://ieeexplore.ieee.org.

Digital Object Identifier 10.1109/TGRS.2007.901032 substantial variation in backscatter from the different land cover 41 types that are adjacent to the flood, the changes in returns from 42 the water surface that are caused by different meteorological 43 conditions, the presence of emergent vegetation, and the effects 44 of man-made structures in urban areas. This paper describes 45 a study to reduce inaccuracies from some of these sources 46 in an existing flood extent delineation algorithm by using an 47 additional data source, namely, airborne laser altimetry.

The simplest model of SAR backscatter from a river flood 49 assumes that the water surface is smoother than the surrounding 50 land and acts as a specular reflector, reflecting radiation away 51 from a side-looking sensor, so that the water appears dark 52 compared to the land. Two factors complicating the simple 53 specular reflection model in practice are the effects of wind 54 or rain roughening of the water surface, and emergent vege- 55 tation. The relationship between SAR backscatter and surface 56 roughness that is caused by wind blowing over the oceans is 57 well understood [3], and the effect may raise the backscatter 58 from the water to similar or greater levels than the adjacent 59 land [4], [5]. Wind roughening of a river flood surface can give 60 rise to similar effects, but these can have substantial spatial 61 variation, depending on the local topography, which determines 62 the fetch for a given wind direction. The presence of emergent 63 vegetation can give rise to multiple reflections between the 64 water and the vegetation, leading to a substantial enhance- 65 ment of backscatter, the magnitude of which is a function 66 of radar wavelength, look angle, and polarization. The effect 67 has been observed in a number of studies of flooded forest 68 and marshland (e.g., [6]-[9]), and the increase in backscatter 69 has been modeled mathematically in [10]. Enhanced backscat- 70 ter from the water surface that is caused by wind roughen- 71 ing or emergent vegetation will also result in an increased 72 level of noise due to the multiplicative nature of noise in 73 SAR images.

A number of methods for the automated delineation of flood 75 extent in SAR imagery of both fluvial and tidal environments 76 have been developed [4], [5], [9], [11]-[21]. Several of these 77 studies have illustrated the great potential of SAR sensors for 78 synoptic observation of large flooding events. An automatic 79 technique for delineating a fluvial flood using a statistical 80 active contour model (or snake) that is applied to a SAR 81 image to identify areas of homogeneous speckle statistics is 82 described in [18] and [19]. This assumes that single-frequency 83 single-polarization SAR intensities are available and was aimed 84 at producing an observed flood extent against which to validate 85 
86 a modeled flood extent. Due to the difficulties of imaging urban 87 areas using SAR, its use is limited to large-area mapping of 88 floods in rural areas. The SAR segmentation uses both local 89 tone and texture measures, and is capable of accurate feature 90 boundary representation. The method was applied to a flood 91 that was imaged using the ERS-1 satellite SAR sensor and 92 proven to be capable of identifying $75 \%$ of the flooded area 93 correctly, with $70 \%$ of the waterline coinciding with ground 94 data within $20 \mathrm{~m}$. The main error in waterline position was 95 found to be due to unflooded short vegetation that was adjacent 96 to the flood giving similar radar returns to open water, causing 97 an overestimation of flood extent. The loss of flood extent due 98 to emergent vegetation was found to be a secondary source 99 of error.

100 Further work on this topic [22], [23] found that, as a result of 101 these error sources and the relatively large size of the European 102 Remote Sensing Satellite (ERS) SAR pixel, the heights of the 103 SAR waterline along a flooded reach could sometimes be in 104 error by several meters (although, generally, it was much less) 105 and could exhibit significant noise. One reason for this was that 106 there was no constraint that the waterline heights should vary 107 smoothly along the reach, whereas, in reality, the longitudinal 108 slope of typical flood flows is low $\left(\sim 0.001-0.0001 \mathrm{~m} \cdot \mathrm{m}^{-1}\right)$, 109 and changes in slope are very gradual. With this level of dif110 ferences, the SAR image becomes much less useful for model 111 flood extent validation than it could otherwise be.

112 Horritt et al. [19] point out that their flood extent map113 ping procedure identifying the flood as a region of rela114 tively homogeneous speckle statistics may be improved by 115 the adoption of a model-based approach. In this vein, this 116 paper describes the use of light detection and ranging (li117 dar) data to modify the SAR waterline, so that it becomes 118 more useful for validation. The snake algorithm [18], [19] 119 is modified to look not only at SAR image space but also 120 at lidar digital terrain model (DTM) and vegetation height 121 maps, so that the snake can be conditioned to be smoothly 122 varying in ground height as well as in SAR intensities and 123 textures. This should reduce errors that are caused by un124 flooded vegetation that is adjacent to the flood giving similar 125 returns to open water and also errors due to the SAR pixel 126 size. It could also help somewhat in reducing errors due to 127 emergent vegetation. An additional benefit of producing a 128 more smoothly varying waterline is that it may allow the 129 development of improved performance measures for flood ex130 tent validation based on patterns of height differences rather 131 than on patterns of wet or dry pixels, as currently done [24]. 132 The algorithm specifically sets out to improve the vertical 133 accuracy of the SAR waterline, although any improvement 134 should also lead to improvement in the horizontal waterline 135 accuracy due to their correlations that are contained within 136 the DTM.

137 Used in this way, the lidar data may actually play a dual 138 role in the modeling process, as lidar is often used to pa139 rameterize the hydraulic model being validated, with the li140 dar DTM providing the model bathymetry and possibly the 141 vegetation heights being used to estimate bottom friction 142 [22]. However, the use of lidar data in SAR waterline ex143 traction as well as model parameterization does not under-

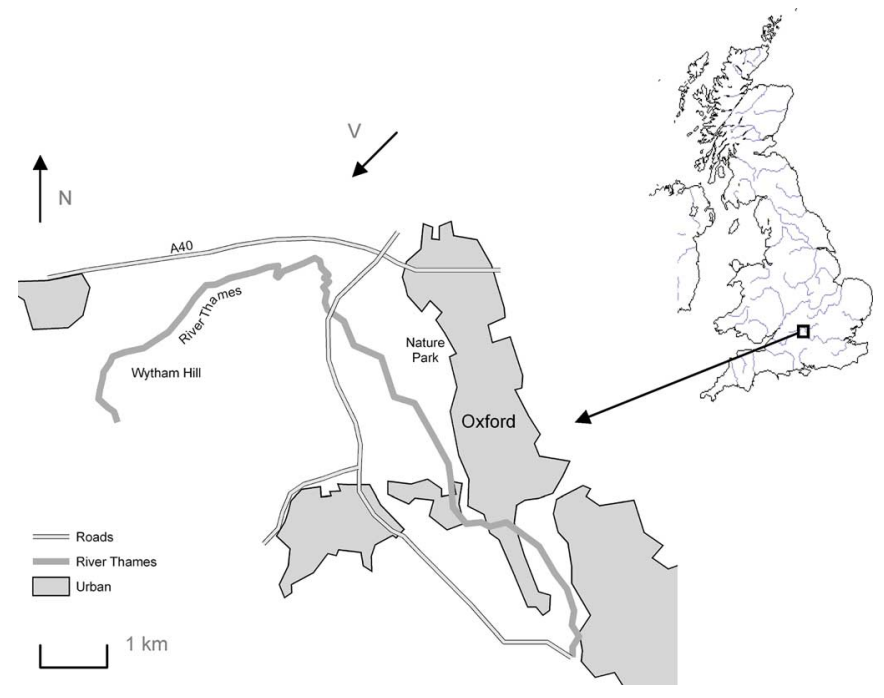

Fig. 1. Location of the test area.

mine the independence of the SAR waterline in the validation 144 process.

\section{Test Data SET}

146

An ideal data set on which to validate the method would be 147 from a flood for which both satellite SAR data and simultaneous 148 aerial photography were available, so that the SAR snake 149 waterlines that are conditioned without and with the lidar data 150 could be compared with the waterline from the aerial pho- 151 tographs. In addition, lidar data of the unflooded area should be 152 available.

Biggin and Blyth [25] acquired oblique aerial photos of a 154 flood on the Thames west of Oxford, U.K., on December 4, 155 1992, at the same time (to within $2 \mathrm{~h}$ ) as an ERS-1 SAR 156 overpass of the area. The Thames is a low-relief slow-response 157 catchment, and at this point along its course, the river discharge 158 during a flood changes only very gradually, so that such timing 159 differences are unimportant. The peak discharge for this event 160 was measured at $76 \mathrm{~m}^{3} \cdot \mathrm{s}^{-1}$, which represents a $\sim 1$-in-5-year- 161 recurrence interval flow. The ERS-1 SAR image was acquired 162 approximately $36 \mathrm{~h}$ after the flood peak when the discharge had 163 dropped to $73 \mathrm{~m}^{3} \cdot \mathrm{s}^{-1}$, indicating the very slow response of the 164 catchment. At the time of overpass, there was no wind or rain in 165 the area. The location of the test area is shown in Fig. 1, and an 166 example of the aerial photography is shown in Fig. 2. The flood- 167 plain over this reach is semirural, with the majority of fields 168 being used at the time for pasture or having been ploughed. 169 There are also several urban areas, and the region is crossed 170 by a number of major roads and railways. The flood waterline 171 was delineated by eye from the aerial photos and vectorized 172 [19]. The waterline vectors were then georeferenced using an 173 orthographic transform that is parameterized by a least squares 174 method using 15-20 control points for each photograph. The 175 error in the waterline position was assessed from waterline 176 segments where the waterline was observed to lie alongside a 177 hedgerow or field boundary that could be located on a 1:25000 178 scale map and was found to be less than $20 \mathrm{~m}$. 


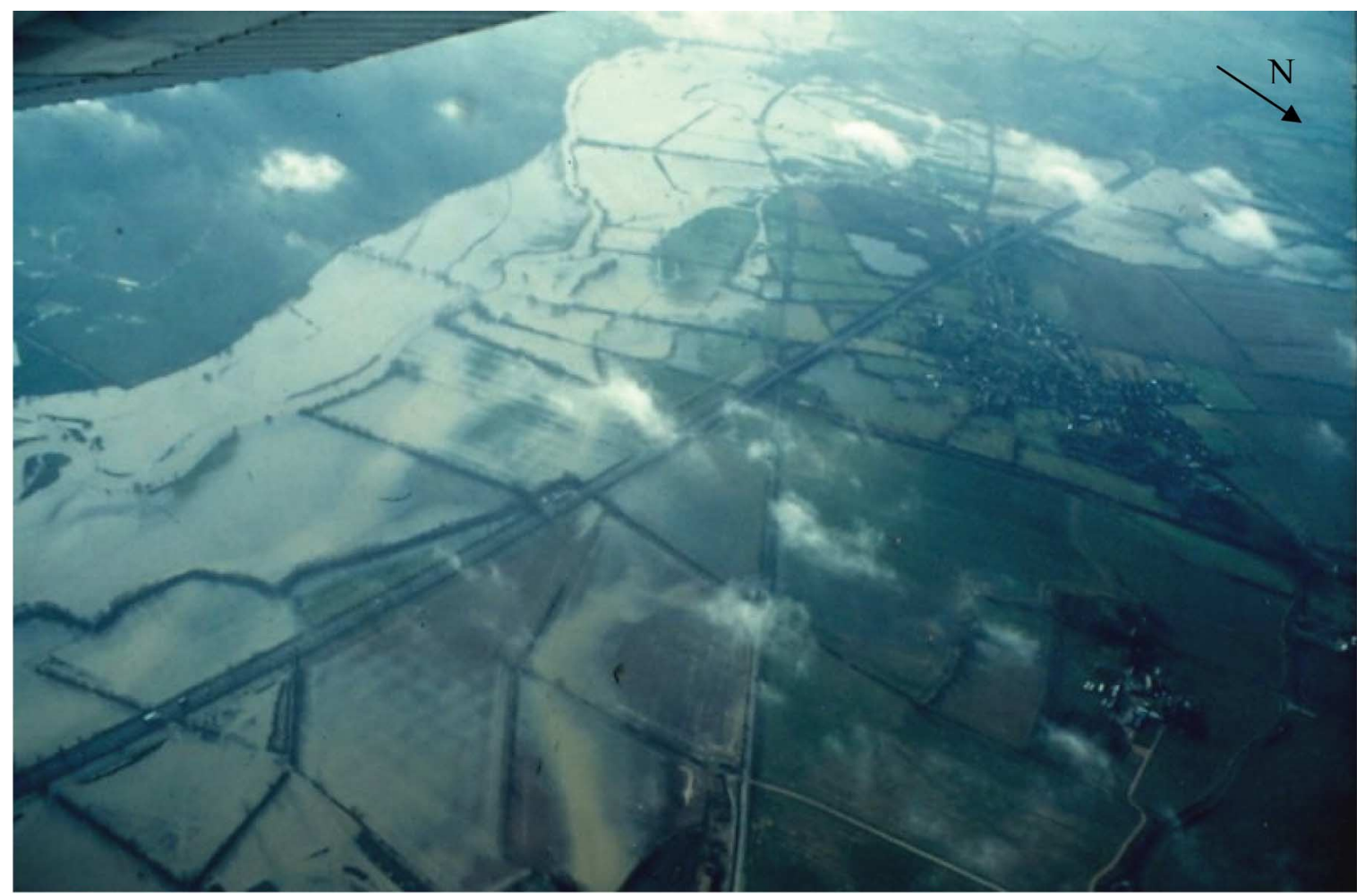

Fig. 2. Example of the aerial photography in the upper section of the reach, looking southwest from the north of the region (the view direction is $\mathrm{V}$ in Fig. 1).

180 Lidar data at 1-m resolution were acquired for a section 181 of this reach west of Oxford and approximately $12 \mathrm{~km}$ long 182 by the Environment Agency of England and Wales (EA). The 183 lidar was an Optech ALTM 2033 that was flown on a Cessna 184 aircraft at $120 \mathrm{kn}$ at a flying height of $900 \mathrm{~m}$, with a laser 185 firing rate of $33 \mathrm{kHz}$, a scanning frequency of $30 \mathrm{~Hz}$, and a 186 scanner half angle of $18^{\circ}$. The lidar heights were validated by 187 the EA by comparing them with a set of global positioning 188 system (GPS) heights of several flat unvegetated surfaces in 189 the area. Based on a sample of 299 GPS readings, the lidar 190 heights were found to have an rms error of $10.6 \mathrm{~cm}$, which 191 comprised a random error of $10.2 \mathrm{~cm}$ and a systematic error 192 of $2.6 \mathrm{~cm}$. Lidar height accuracy reduces on steeper slopes 193 and in vegetated regions [26]. Lidar positional accuracy was 194 about $0.4 \mathrm{~m}$ [27]. The postprocessed lidar DTM and vege195 tation height mask were obtained from the EA. These were 196 degraded to 2-m pixel size to avoid too large a mismatch 197 with the SAR pixel size of $12.5 \mathrm{~m}$. Fig. 3 shows the lidar 198 DTM with the high land of Wytham Hill in the west and the 199 raised Oxford Nature Park in the east (see Fig. 1), both of 200 which are relevant to this study. Fig. 3 also shows the aerial 201 photo waterline overlain on the lidar DTM, with the waterline 202 color representing its difference in height from the local mean 203 waterline height (within $0.5-\mathrm{km}$ distance). The presence of 204 large sections of waterline having small differences (blue color) 205 from the local mean height indicates that the aerial waterline 206 height varies smoothly along the reach. The waterline includes 207 instances of islands of higher ground that are surrounded by 208 water. It is assumed here that all areas of water have been 209 accurately mapped, so that the validation data are essentially 210 error free.

\section{Flood Extent Extraction From SAR Data}

\section{A. Algorithm Description}

A detailed description of the algorithm to delineate a flood 213 using an active contour model is given in [18], and only an 214 overview is presented here. Active contour models or snakes 215 are useful for converting incomplete or noisy edge maps into 216 smooth continuous vector boundaries [5], [28]. The edge image 217 space is searched using a dynamic curvilinear contour that is 218 driven to be attracted to edge pixels using an energy minimiza- 219 tion function, so that the contour can link together unconnected 220 edge segments. The contour (snake) is represented in a piece- 221 wise linear fashion as a set of nodes (i.e., the coordinates of the 222 snake points) that are linked by straight-line segments. Ivins 223 and Porrill [29] developed a statistical snake that operates on 224 the image itself rather than an edge image, dispensing with the 225 need for a prior edge detection stage. Their technique involves 226 estimating the local image mean intensity (tone) at a node using 227 the pixels between this node and its adjacent nodes. This gives 228 the advantage that noise due to SAR speckle is reduced by 229 averaging pixel intensities along an edge while, at the same 230 time, maintaining resolution that is perpendicular to the edge, 231 giving accurate edge positioning. The local intensity variance 232 (texture) is also calculated from these pixels, as this has proven 233 to be a useful discriminator between different natural land- 234 cover types having similar mean intensities in SAR imagery. 235

The statistical snake is formulated as an energy minimization 236 problem with the total snake energy $E(\boldsymbol{u}(s))$ given by

$E(\boldsymbol{u}(s))=E_{\text {tension }}+E_{\text {curvature }}-\iint G(I(x, y)) d x d y$ 


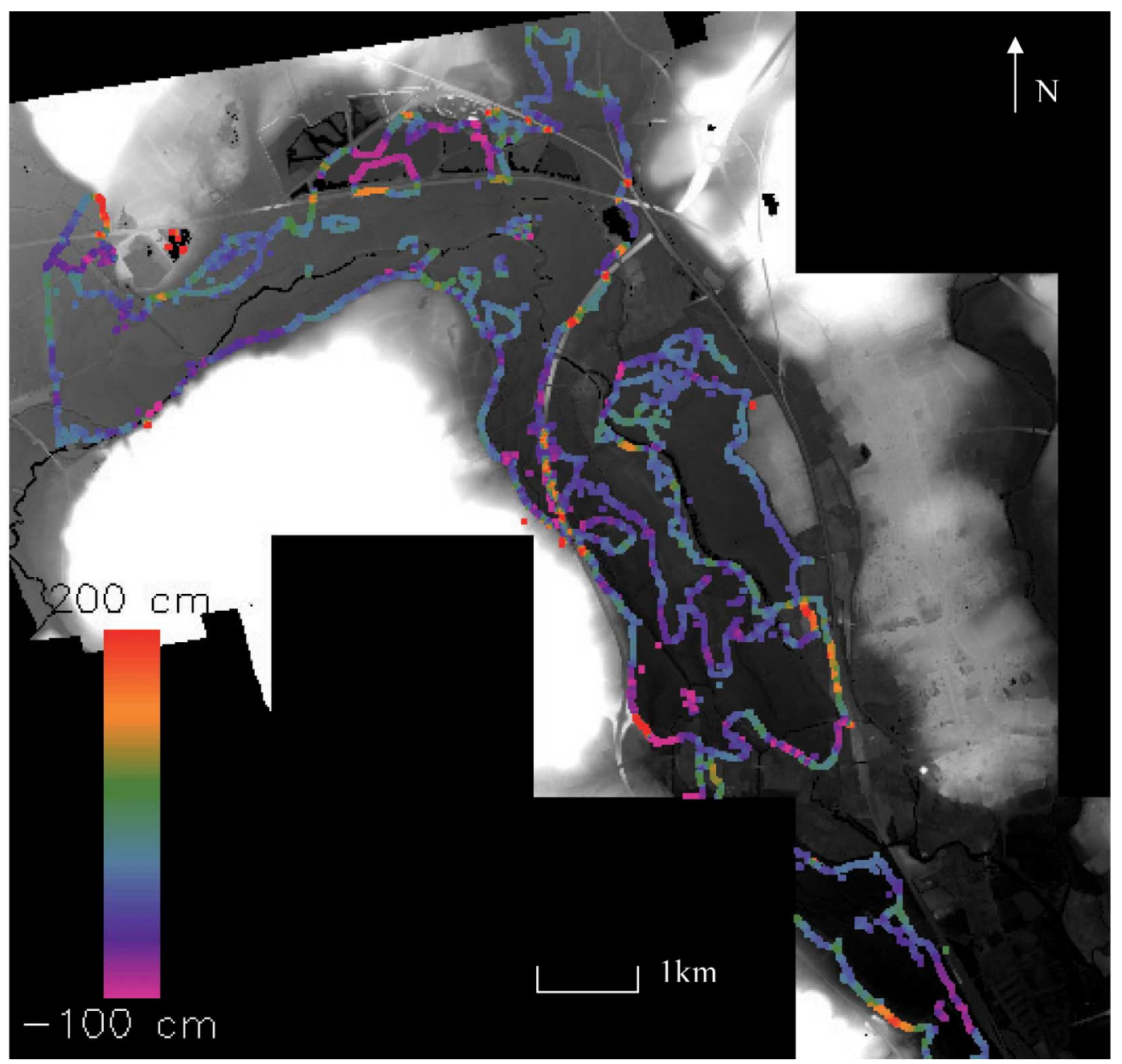

Fig. 3. Aerial photo waterline overlain on the lidar DTM. The colors represent the difference in height of the waterline from the local mean waterline height.

238 where $\boldsymbol{u}(s)=(x(s), y(s))$ describes the contour position $(x, y)$ 239 in the 2-D image space as a vector function of arc length 240 parameter $s$. $E_{\text {tension }}$ and $E_{\text {curvature }}$ are energies that are gen241 erated by the model's internal tension and stiffness constraints, 242 which favor a smooth uncrenellated contour that is made up 243 of evenly spaced nodes (see the following). $G$ is a goodness 244 function that assesses how well a set of image pixels $I(x, y)$ 245 meets certain criteria. The total energy is minimized if the con246 tour encloses a region of pixels that is homogeneous in tone and 247 texture.

248 If the mean and variance of the intensities of the set of pixels 249 that are immediately at either side of a particular snake node are 250 measured, the knowledge of how these variables are distributed 251 can be used to estimate the probability that these pixels match 252 those that are already within the region that is enclosed by the 253 contour. Horritt [18] relates $G$ to the $\log$ of this probability, with 254 the dependence on the measured sample mean $\mu^{\prime}$, for example, 255 having the form

$$
G\left(\mu^{\prime}\right)=1-n\left(\mu^{\prime}-\mu\right)^{2} / v k^{2}
$$

256 where $\mu$ and $v$ are the mean and variance of the seed population 257 that is already enclosed within the contour, respectively; $n$ is the sample size; and $k$ is a parameter that can be adjusted 258 to tune algorithm performance. $G$ is then equal to 1 for a 259 set of pixels with the expected mean but falls to zero if the 260 mean differs by $k \sqrt{ }(v / n)$ (i.e., $k$ standard deviations) from 261 the expected value. The parameter $k$ is usually set at about 262 2 or 3 but may be increased further to allow for a level of 263 statistical inhomogeneity in the region being segmented. The 264 overall goodness function (with components that are based on 265 both the measured mean and variance) is limited to a minimum 266 value of -1 .

The roles of the tension and curvature constraints are to pro- 268 duce a contour of appropriate smoothness with evenly spaced 269 nodes, by a consideration of the balance between image and 270 curvature forces. Consider the situation that is shown in Fig. 4271 for snake nodes at $\boldsymbol{u}_{i-1}, \boldsymbol{u}_{i}$, and $\boldsymbol{u}_{i+1}$ that are linked by unit 272 vectors $\boldsymbol{v}_{i}$ and $\boldsymbol{v}_{i+1}$. The local curvature is $\Delta \theta / \Delta s$, where $\Delta \theta 273$ is the change of angle along arc length $\Delta s$. Horritt [18] gives 274 the contribution to the total curvature energy as

$$
\Delta E_{\text {curvature }}=\gamma(\Delta \theta / \Delta s)^{2} / \Delta s=\gamma\left|\boldsymbol{v}_{i+1}-\boldsymbol{v}_{i}\right|^{2} / a_{i}
$$

where $a_{i}$ is the distance between the midpoints of $\boldsymbol{v}_{i}$ and $\boldsymbol{v}_{i+1}, 276$ and $\gamma$ is a curvature energy weighting parameter. Equation (3) 277 


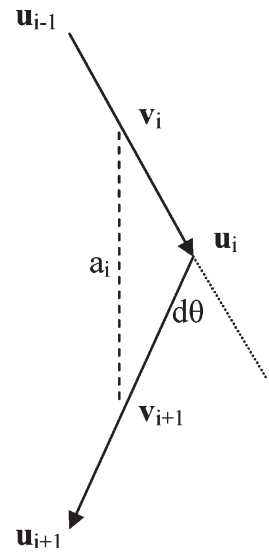

Fig. 4. Vectors for describing curvature and tension energies (after [18]).

278 is valid for small values of $\Delta \theta$. Similarly, the contribution to 279 the tension energy is given by

$$
\Delta E_{\text {tension }}=\lambda\left(\left|\boldsymbol{u}_{i+1}-\boldsymbol{u}_{i}\right|^{2}+\left|\boldsymbol{u}_{i}-\boldsymbol{u}_{i-1}\right|^{2}\right)
$$

280 where $\lambda$ is the tension energy weighting parameter. The mag281 nitudes of these energies can be adjusted using the weighting 282 parameters. Too large a value for the curvature parameter 283 will make the curvature term dominate the model energy and 284 produce an unrealistically smooth contour. Too large a value of 285 the tension parameter will favor a short contour and stifle the 286 growth of the snake.

287 The scheme that was used to minimize the energy is the 288 algorithm of Williams and Shah [28]. For each node at each 289 iteration, the change in energy $d E$ is computed for moves to all 290 eight neighbors of the node

$$
d E=-G d A+d E_{\text {tension }}+d E_{\text {curvature }}
$$

291 The lowest (most negative) $d E$ is chosen. Obviously, $d E$ is 292 equal to zero for no node movement. $G$ is calculated along the 293 line segments linking the node with its two neighbors, and $d A$ is 294 the local change in area. If $G$ is positive, the snake is in a region 295 of homogeneous pixels, a positive $d A$ is favored, and the snake 296 expands. If $G$ is negative, the snake is in an inhomogeneous re297 gion, a negative $d A$ is favored, and the snake retreats. The mean 298 and standard deviation of the seed population are calculated 299 from all pixels lying inside the contour every ten iterations.

300 The flooded region may not be simply connected, as islands 301 and isolated water bodies may form holes and outliers. To cope 302 with this, the algorithm incorporates a method for dealing with 303 complex topology and snake self-intersection. As an example, 304 a snake may spawn a smaller subsnake within itself to represent 305 an island.

\section{B. Implementation and Qualitative Assessment of Results}

307 A personal computer (PC)-based implementation of the al308 gorithm (Psnake NT) was used in this paper [30]. Psnake NT 309 is a software package that is available to the hydrological 310 modeling community for the semiautomatic extraction of flood

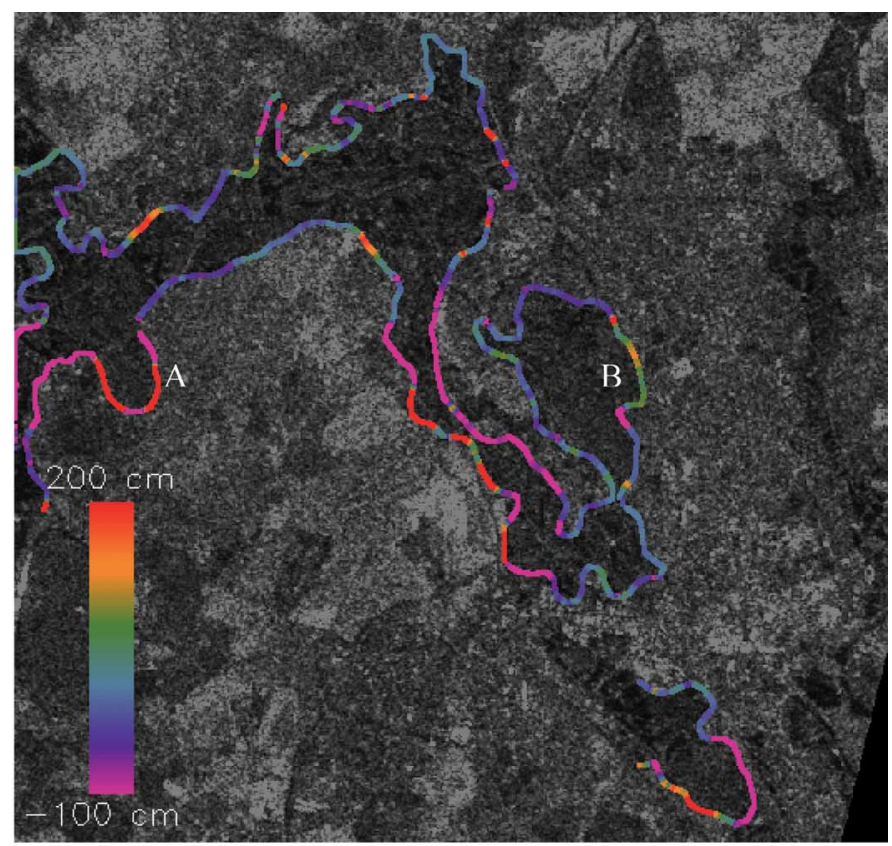

(a)

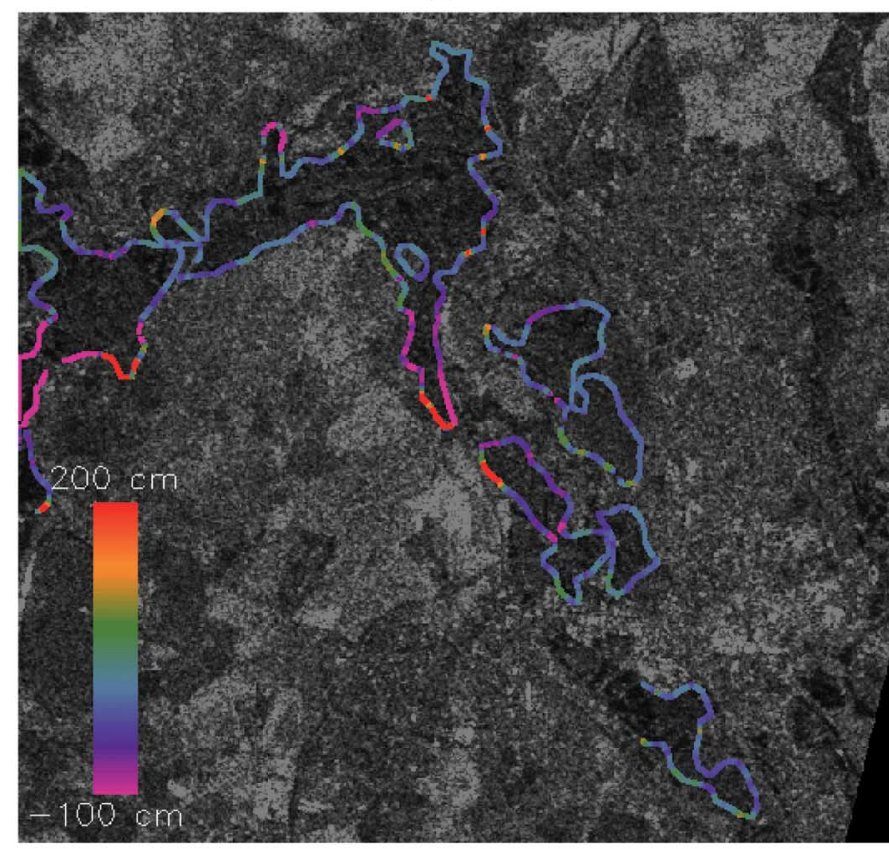

(b)

Fig. 5. Waterline conditioned only on SAR data overlain on SAR data (a) for parameter $k=3$ and (b) $k=2$. The colors represent the difference in height of the waterline from the local mean waterline height.

extents from SAR data. Fig. 5 shows snake waterlines that are 311 generated using SAR data only, for the number of standard 312 deviations $k$ of 3 and 2, overlain on SAR data. It has been found 313 by experiment that $k$ is probably the most important parameter 314 controlling the snake [19]. Other parameter settings were a 315 minimum node spacing of 6 pixels, a maximum node spacing 316 of 12 pixels, curvature parameter $\gamma$ of 68.3 , tension parameter $\lambda 317$ of 0.1 , a texture weight of 0.2 , and iterations of 200 . The snake 318 was seeded (i.e., initialized) manually as a narrow strip lying 319 


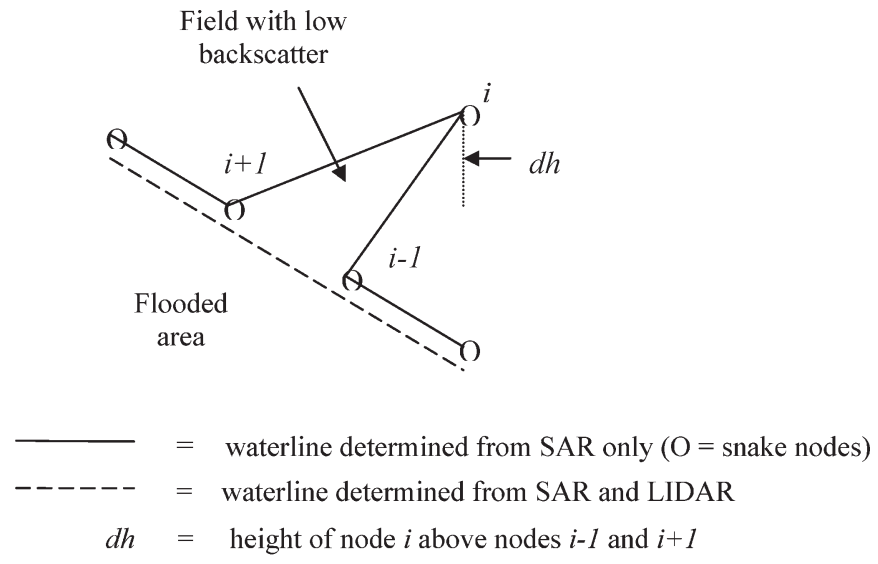

Fig. 6. Example error that might be corrected using lidar.

320 along the course of the unflooded river channel, ensuring that 321 it contained only flooded pixels.

322 In Fig. 5, the snake shows a tendency to leak onto higher 323 ground on Wytham Hill [point A in Fig. 5(a), see also Fig. 3]. 324 This is likely to be due to the presence of vegetated fields, 325 which correspond to areas of low SAR backscatter and are 326 likely to be misclassified as flooded. While no ground reference 327 data were acquired at the time of the flood, evidence for this 328 comes from a recent aerial photograph that was obtained later 329 than the SAR image. A further example of leakage of the snake 330 onto higher ground is visible at point B in Fig. 5(a), where 331 the snake has leaked onto the Oxford Nature Park, which is 332 higher than the land toward the Thames yet again exhibits low 333 SAR backscatter.

\section{$334 \quad$ IV. Flood EXTENT EXTRACTION FROM \\ $335 \quad$ SAR AND LIDAR DATA}

\section{A. Algorithm Modification}

337 The snake algorithm was modified so that the snake was 338 conditioned not only on the SAR image but also on the lidar 339 DTM, so that it becomes smoothly varying in ground height as 340 well as in SAR intensities and textures. The principle that was 341 adopted was that the SAR image should still be the primary 342 determinant of the flood extent. In most areas, the flood extent 343 that was determined by the SAR will be correct within the SAR 344 resolution, but where errors creep in the lidar can help to correct 345 these.

346 The lidar DTM is able to provide a ground height at each 347 pixel, so that each position $\boldsymbol{u}(x, y)$ becomes $\boldsymbol{u}(x, y, z)$. The 348 modification involves using the lidar heights to measure curva349 tures and tensions at snake nodes in 3-D rather than 2-D space. 350 Consider an instance where an unflooded field with low SAR 351 backscatter is adjacent to a flood edge, such that the field is 352 included in the SAR waterline determined by the snake (Fig. 6). 353 As there will likely be a rise in height $(d h)$ across the field 354 that is perpendicular to the true flood edge, the error in the 355 waterline will give rise to a significant component of curvature 356 in the vertical plane, which will not be present in the waterline 357 segments that are adjacent to the field. To be specific, in Psnake
NT, the contribution to the 3-D curvature energy at the snake 358 node at $\boldsymbol{u}\left(x_{i}, y_{i}, z_{i}\right)$ from its two adjacent nodes is

$$
\Delta E_{\text {curvature }}=\gamma\left|\boldsymbol{v}_{i+1}-\boldsymbol{v}_{i}\right|^{2} / a_{i}=\left(c_{i x}^{2}+c_{i y}^{2}+c_{i z}^{2}\right) / a_{i}
$$

where

$$
\begin{aligned}
c_{i x}= & \left(x_{i+1}-x_{i}\right) / d_{i+1}-\left(x_{i}-x_{i-1}\right) / d_{i} \\
c_{i y}= & \left(y_{i+1}-y_{i}\right) / d_{i+1}-\left(y_{i}-y_{i-1}\right) / d_{i} \\
c_{i z}= & \left(z_{i+1}-z_{i}\right) / d_{i+1}-\left(z_{i}-z_{i-1}\right) / d_{i} \\
d_{i}= & \left(\left(x_{i}-x_{i-1}\right)^{2}+\left(y_{i}-y_{i-1}\right)^{2}+\left(z_{i}-z_{i-1}\right)^{2}\right)^{0.5} \\
d_{i+1}= & \left(\left(x_{i+1}-x_{i}\right)^{2}+\left(y_{i+1}-y_{i}\right)^{2}+\left(z_{i+1}-z_{i}\right)^{2}\right)^{0.5} \\
a_{i}= & \left(\left(\left(x_{i+1}+x_{i}\right) / 2-\left(x_{i}+x_{i-1}\right) / 2\right)^{2}\right. \\
& \quad+\left(\left(y_{i+1}+y_{i}\right) / 2-\left(y_{i}+y_{i-1}\right) / 2\right)^{2} \\
& \left.\quad+\left(\left(z_{i+1}+z_{i}\right) / 2-\left(z_{i}+z_{i-1}\right) / 2\right)^{2}\right)^{0.5}
\end{aligned}
$$

and the suffixes refer to the node numbers in Fig. 6. To reduce 361 the vertical curvature component $c_{i z}^{2}$ at node $i$ in Fig. 6, the 362 snake will try to contract to drag node $i$ back to be collinear 363 with nodes $i-1$ and $i+1$, which will also reduce $c_{i x}^{2}$ and $c_{i y}^{2} .364$ The 3-D tension energy, which is proportional to $\left(d_{i+1}^{2}+d_{i}^{2}\right), 365$ will also be reduced by this move.

A waterline error due to the presence of emergent vegetation 367 at the edge of the flood might also have significant components 368 of vertical curvature and tension that could be reduced by 369 correcting the error. A complicating factor in this case is that 370 the SAR and lidar forces might be acting against each other. In 371 order to reduce the vertical curvature and tension by incorporat- 372 ing the area of enhanced backscatter into the flooded area, the 373 inhomogeneity of the SAR returns in the flooded area would 374 generally have to increase. Which force won out in a particular 375 case would depend on their relative strengths. However, this 376 effect is not the dominant source of error [19].

In order to take account of the fact that a change in height at 378 a node should, in general, cause different changes in curvature 379 and tension compared to the same magnitude change of node 380 position in the $x y$ plane, the lidar heights were scaled by 381 weighting factor $w_{l}$ with respect to the $(x, y)$ coordinates. 382

The straightforward approach to combining the SAR and 383 lidar data would be to use the existing algorithm with both 384 data sets and simply calculate 3-D rather than 2-D curvature 385 and tension energies. A possible objection to this might be that, 386 if there were flooded mounds in the floodplain that are not 387 visible to the SAR but visible to the lidar, these might retard 388 the expansion of the snake and distort the eventual waterline. 389 An alternative approach could be to use the algorithm with 390 SAR data and 2-D curvatures and tensions only initially. Then, 391 the snake iterations could continue using SAR and lidar data, 392 and 3-D curvatures and tensions, causing the snake to adjust 393 itself to correct errors where necessary. However, in cases 394 where the waterline was significantly in error, it might be 395 difficult to recover from these errors. For example, if the snake 396 leaked onto higher ground, it might be impeded from returning 397 to the true waterline position by a hollow in the higher ground. 398 In practice, it turns out that the straightforward approach using 399 
400 the existing algorithm and calculating 3-D curvatures and ten401 sions works well enough.

402 The SAR data may have significantly lower resolution than 403 the airborne lidar data, as in the present test data set comprising 404 ERS satellite SAR data. In this case, it may be possible to 405 correct the waterline position to sub-SAR pixel accuracy in a 406 second pass of the algorithm. The idea would be to rescale the 407 SAR image and the snake waterline from the first pass to the 408 higher resolution of the lidar, and to continue iterating to try to 409 move the snake nodes away from the centers of the enlarged 410 SAR pixels to create a waterline varying more smoothly in 411 height along its length. A constraint would be that a node should 412 not be allowed to move outside its enlarged SAR pixel, as no 413 further information could be extracted from the SAR image at 414 this stage.

\section{B. Implementation and Qualitative Assessment of Results}

416 For the first pass of the modified algorithm, the lidar image 417 was degraded to the same pixel size as the SAR image (12.5 m) 418 by averaging the lidar heights within each SAR pixel. The 419 parameter settings for this pass were the same as those for the 420 snake that was conditioned on only the SAR data (other than for $421 k$ and $w_{l}$ ). The initial value of lidar weight factor $w_{l}$ was chosen 422 by experiment to be 0.15 . This took into account the fact that 423 the leakage at Wytham Hill [at point A in Fig. 5(a)] occurs over 424 a distance of about $0.5 \mathrm{~km}$. Curvature at a node is calculated 425 using the two adjacent nodes on either side of the central node, 426 spanning four internode spacings. For an internode spacing of 427 eight pixels, this corresponds to a distance of about $400 \mathrm{~m}$, 428 roughly matching that required. The $w_{l}$ setting also reflected 429 the facts that the lidar heights were expressed in millimeters 430 and that a, for example, 1000-mm rise in the lidar height of the 431 central node should give rise to a significant increase in 3-D 432 curvature. Even though a node can only be moved horizontally 433 by one SAR pixel at each iteration, this still amounts to a 434 horizontal shift of $12.5 \mathrm{~m}$, which is large compared to a $1-\mathrm{m}$ 435 vertical rise.

436 The original snake seed that was used contained only pixels 437 south of the A40 road west of Oxford (Fig. 1), and it was 438 found on the first pass that, with the 3-D curvature constraint, 439 the snake would not expand into the flooded areas north of the 440 embanked road, even though this was, on average, only $1.5 \mathrm{~m}$ 441 higher than the fields surrounding it. In practice, floodwater 442 from the Thames flows under the A40 onto the lower land 443 to the north through culverts that are spaced at about 250-m 444 intervals. To overcome this difficulty, additional snake seed 445 pixels were inserted to the north of the A40, which were 446 then able to expand into the northernmost part of the flooded 447 region. The same snake seed was used for all snakes that 448 were generated, whether they were conditioned using the lidar 449 data or not.

450 The second pass took place at higher resolution, i.e., at the $4512-\mathrm{m}$ pixel spacing of the lidar data. The input to this pass was 452 the snake output from the first pass, with the node coordinates 453 scaled up by 6.25 to match the change in resolution. The 454 SAR image was interpolated from 12.5 to $2 \mathrm{~m}$ using nearest 455 neighbor interpolation. The number of iterations was set to 3 ,

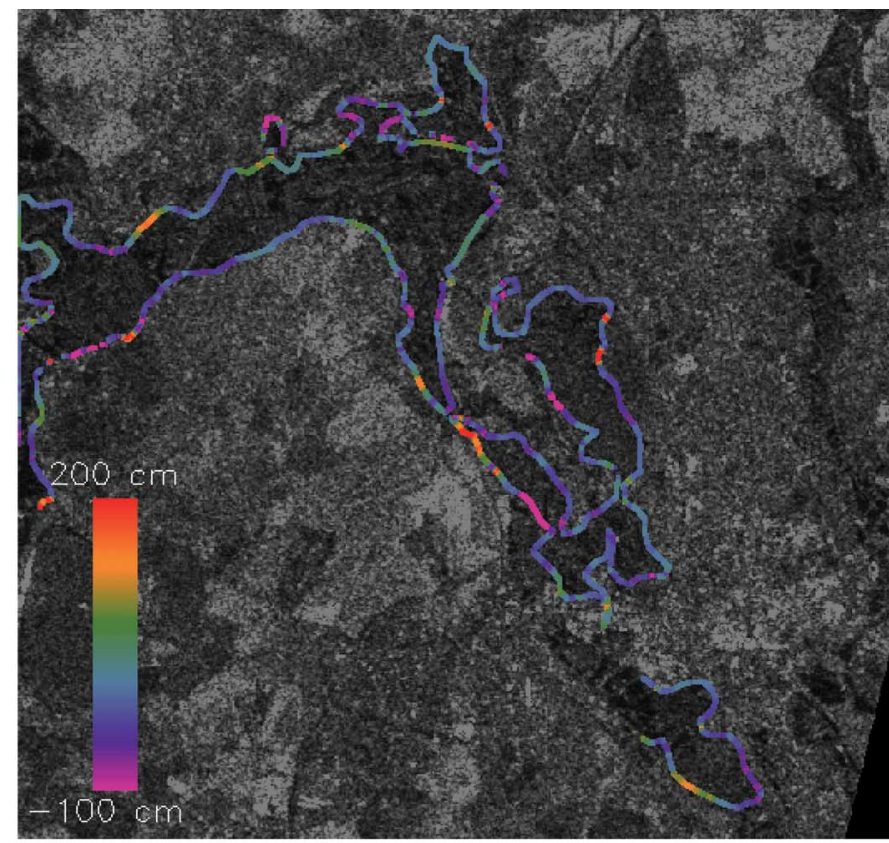

(a)

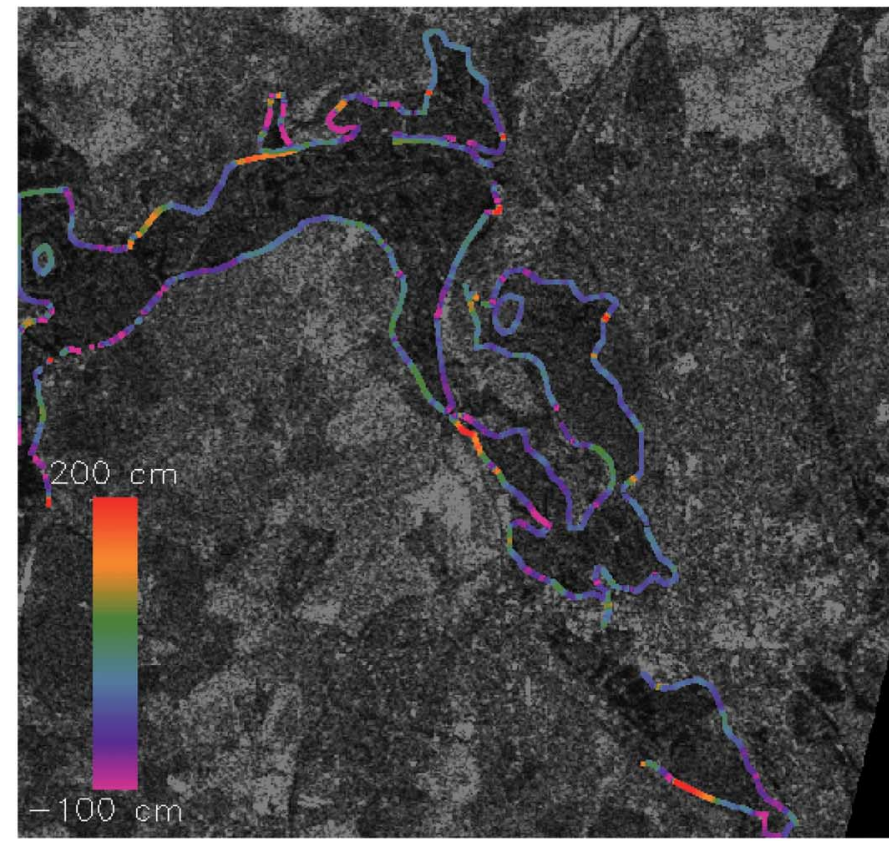

(b)

Fig. 7. Waterline conditioned on SAR and lidar data overlain on SAR data (a) for parameter $k=3$ and $w_{l}=0.15$, and (b) for $k=4$ and $w_{l}=0.15$. The colors represent the difference in height of the waterline from the local mean waterline height.

to ensure that the snake nodes would not move outside the SAR 456 pixels within which they had stabilized after the first pass. The 457 minimum and maximum node spacings were also upscaled to 458 37 and 74 pixels, respectively, ensuring similar 3-D curvatures 459 to those on the first pass.

Fig. 7 shows snake waterlines that were conditioned on both 461 SAR and lidar data, for $k$ values of 3 and 4 and lidar weight 462 $w_{l}=0.15$, overlain on 12.5-m SAR data. It is clear that the 463 tendency for the snake to leak to higher ground at Wytham Hill 464 and at the Oxford Nature Park has been much reduced (see 465 
466 also Fig. 3). A further benefit is that the snake appears to be 467 more stable to parameter changes. For example, in Fig. 5, the 468 snake that was conditioned only on SAR data shows substantial 469 change when $k$ is raised from 2 to 3, whereas in Fig. 7, the snake 470 that was conditioned on SAR and lidar shows less change when $471 k$ is raised from 3 to 4 . This finding is born out more rigorously 472 in the quantitative analysis described in the next section.

473 The main errors in waterline position that were corrected 474 using the lidar data are due to the unflooded short vegetation 475 that is adjacent to the flood giving similar returns to open water. 476 The ability of the algorithm to correct loss of flood extent due to 477 emergent vegetation is hardly tested using this data set, as this 478 has few significant examples. The most obvious instances are 479 emergent hedges between adjacent flooded fields, but these are 480 generally of insufficient area to stop the snake subsuming them 481 into its interior, even if conditioned only on SAR data.

\section{V. PARAMETER Optimization And QuAntitative 483 COMPARISON OF METHODS}

484 The snake parameters were optimized using a quantitative 485 measurement of algorithm performance. The snake and aerial 486 photo waterlines were first heighted by superimposing them 487 on the lidar DTM. The snake waterline is defined only at the 488 snake nodes. Only nodes on low slopes and in areas of short 489 vegetation in the lidar vegetation height map were selected for 490 heighting, as these are the ones that are likely to be heighted 491 most accurately. The lower the slope, the smaller the node 492 height error for a given error in its position. No requirements 493 were made that selected nodes should have a strong SAR edge 494 [indicated by a low $G$ value (2)] associated with them, as this 495 would reject nodes at the boundaries between the flood and 496 an unflooded field giving low SAR backscatter, or between a 497 region of emergent vegetation at the flood edge and an adjacent 498 unflooded land (both giving high SAR backscatter).

499 For each snake node that was selected, the aerial photo height 500 to associate with the snake height was found by finding the 501 height of the closest aerial photograph waterline point. This 502 was found by applying a distance-with-destination transform to 503 the aerial photo waterline image. The distance-with-destination 504 transform is a form of distance transform that stores, for each 505 pixel in the transform image, its distance to the nearest wa506 terline point and also the direction from which the minimum 507 distance was propagated. This allows backtracking from a 508 pixel to find its nearest waterline point [31]. Corroborating the 509 finding of [19], the average separation distance was about $50 \mathrm{~m}$, 510 although this value was strongly influenced by a small number 511 of pairs having large separations, and the average separation 512 of $70 \%$ of the pairs having separations of less than $50 \mathrm{~m}$ 513 was only $20 \mathrm{~m}$. However, the pairs with large separation were 514 not rejected, as they included examples where, e.g., the SAR 515 waterline was displaced from the aerial photo waterline by a 516 complete field width due to misclassification of the field as 517 flooded. The anticipation was that these events would be less 518 common when the snake was conditioned on the SAR and lidar 519 data than on the SAR data alone.

520 Parameters were optimized by minimizing the sum of the 521 squared height differences between the snake nodes and their corresponding aerial photo waterline points. To ensure that 522 adjacent pairs of heights were largely uncorrelated, the pairs 523 that were selected so far were thinned further, so that no 524 pair was closer than $200 \mathrm{~m}$ to another. This distance was 525 estimated by constructing a correlogram from the set of pairs 526 [32] and was the distance at which the average correlation 527 between adjacent pairs became less than 0.2. From the remain- 528 ing pairs, the mean and standard deviations of the snake and 529 aerial photograph waterline heights were calculated, as was 530 the rms error of the height differences, with this being the 531 variable to minimize in the parameter optimization. The mean 532 height difference and the standard deviation of the differences 533 were also calculated, and this allowed a paired t-test to be 534 performed to test whether the differences were significantly 535 nonzero. The paired t-test is used to exploit the fact that, while 536 corresponding SAR and aerial photograph waterline heights 537 will be correlated due to the gradual drop in height along the 538 reach, the height differences at corresponding nodes will be 539 uncorrelated due to the thinning process, as required by the 540 paired test.

541

Only the most important parameters were investigated in the 542 optimization procedure. For the snake that was conditioned 543 on only SAR data, the parameter that was optimized was $k .544$ For the snake that was conditioned on SAR and lidar data, $k 545$ and $w_{l}$ were optimized.

546

Table I(a) shows the results of varying $k$ for the snake that 547 was conditioned on only the SAR data. The minimum rms error 548 is $221.1 \mathrm{~cm}$, which was obtained for $k=2.0$. The associated 549 high $t$ value implies that there is a significant height difference 550 at the $5 \%$ level between the snake and aerial photo waterlines. 551 The corresponding snake is shown in Fig. 5(b). Higher values 552 of $k$ give significantly larger rms errors, and the high $t$ values 553 that were coupled with positive mean height differences imply 554 that, for all these $k$ values, the snake waterline heights are 555 significantly higher than those of the aerial photograph. 556

Table I(b) shows the results of varying $k$ for the snake that 557 was conditioned on SAR and lidar data, with $w_{l}$ held constant 558 at 0.15 . The minimum rms error is $55.5 \mathrm{~cm}$, which was obtained 559 for $k=3.0$. The associated $t$ value is not significantly nonzero, 560 so that there is no significant difference between the snake 561 and aerial photo waterline heights. The corresponding snake is 562 shown in Fig. 7(a).

Table I(c) shows the results of varying $w_{l}$ for the snake that 564 was conditioned on SAR and lidar data, with $k$ held constant 565 at 3.0. The minimum rms error is obtained at $w_{l}=0.15$. Over 566 the ranges of $k$ and $w_{l}$ that were investigated, none of the $t 567$ values are significantly nonzero, implying greater robustness 568 to parameter changes than the case for the snake that was 569 conditioned on only SAR data.

Table II gives the frequency tables of the absolute differences 571 of the paired heights for the parameter sets giving the minimum 572 rms errors for the snake that was conditioned on only the SAR 573 data and the snake that was conditioned on SAR and lidar data. 574 It can be seen that the increase in the rms error in the case of 575 the snake that was conditioned only on SAR data is due almost 576 entirely to the large number of pairs having height differences 577 of greater than $300 \mathrm{~cm}$. This is also apparent in Fig. 8, where 578 the paired height differences for the two cases are plotted as a 579 
TABLE I

RESUltS OF (a) VARYING $k$ FOR THE SNAKE CONDITIONED ON ONLY THE SAR DATA, (b) VARYING $k$ FOR THE SNAKE CONDITIONED ON SAR AND LidAR DATA, WITH $w_{l}$ HELd CONSTANT AT 0.15, AND (c) VARYING $w_{l}$ FOR THE SNAKE CONDITIONED ON SAR AND LIDAR DATA, With $k$ HELD CONSTANT AT 3.0

\begin{tabular}{|c|c|c|c|c|c|c|}
\hline$k$ & $\begin{array}{c}\text { Number of } \\
\text { height } \\
\text { pairs }\end{array}$ & $\begin{array}{c}\text { R.m.s. } \\
\text { error in } \\
\text { height } \\
(\mathrm{cm})\end{array}$ & $\begin{array}{c}\text { Mean } \\
\text { height } \\
\text { difference } \\
(\mathrm{cm})\end{array}$ & $t_{0}$ & $\begin{array}{c}\text { Probability } \\
t>\left|t_{0}\right| \\
\text { (one-sided } \\
\text { test) }\end{array}$ & $\begin{array}{c}\text { Relative } \\
\text { height } \\
\text { standard } \\
\text { deviation } \\
(\mathrm{cm})\end{array}$ \\
\hline 1.5 & 165 & 238.8 & 31.6 & 1.7 & 0.04 & 105.3 \\
\hline 2.0 & 200 & 221.1 & 33.7 & 2.2 & 0.02 & 136.2 \\
\hline 2.5 & 197 & 381.3 & 65.4 & 2.4 & 0.01 & 263.1 \\
\hline 3.0 & 195 & 331.4 & 64.5 & 2.8 & 0.004 & 314.4 \\
\hline 4.0 & 206 & 317.5 & 70.7 & 3.3 & 0.0005 & 379.1 \\
\hline
\end{tabular}

(a)

\begin{tabular}{|c|c|c|c|c|c|c|}
\hline$k$ & $\begin{array}{c}\text { Number of } \\
\text { height } \\
\text { pairs }\end{array}$ & $\begin{array}{c}\text { R.m.s. } \\
\text { error in } \\
\text { height } \\
(\mathrm{cm})\end{array}$ & $\begin{array}{c}\text { Mean } \\
\text { height } \\
\text { difference } \\
\text { (cm) }\end{array}$ & $t_{0}$ & $\begin{array}{c}\text { Probability } \\
t>\left|t_{0}\right|\end{array}$ & $\begin{array}{c}\text { Relative } \\
\text { height } \\
\text { standard } \\
\text { deviation } \\
\text { (cm) }\end{array}$ \\
\hline 2.8 & 195 & 57.8 & -1.5 & -0.4 & 0.35 & 43.5 \\
\hline 3.0 & 191 & 55.5 & -4.3 & -1.0 & 0.15 & 42.6 \\
\hline 3.2 & 190 & 86.6 & -3.1 & -0.5 & 0.30 & 52.6 \\
\hline 3.5 & 195 & 120.8 & 5.2 & 0.6 & 0.28 & 65.4 \\
\hline 4.0 & 195 & 63.7 & 4.5 & 1.0 & 0.15 & 48.9 \\
\hline
\end{tabular}

(b)

\begin{tabular}{|c|c|c|c|c|c|c|}
\hline$w_{l}$ & $\begin{array}{c}\text { Number of } \\
\text { height } \\
\text { pairs }\end{array}$ & $\begin{array}{c}\text { R.m.s. } \\
\text { error in } \\
\text { height } \\
(\mathrm{cm})\end{array}$ & $\begin{array}{c}\text { Mean } \\
\text { height } \\
\text { difference } \\
(\mathrm{cm})\end{array}$ & $t_{0}$ & $\begin{array}{c}\text { Probability } \\
t>\left|t_{0}\right|\end{array}$ & $\begin{array}{c}\text { Relative } \\
\text { height } \\
\text { standard } \\
\text { deviation } \\
(\mathrm{cm})\end{array}$ \\
\hline 0.10 & 187 & 90.2 & -0.1 & -0.1 & 0.46 & 47.4 \\
\hline 0.14 & 196 & 61.0 & 5.4 & 1.2 & 0.10 & 43.0 \\
\hline 0.15 & 191 & 55.5 & -4.3 & -1.0 & 0.15 & 42.6 \\
\hline 0.16 & 191 & 55.8 & 0.7 & 0.2 & 0.42 & 43.5 \\
\hline 0.20 & 195 & 81.5 & -9.0 & -1.5 & 0.07 & 54.7 \\
\hline
\end{tabular}

(c)

580 function of distance downstream. The main effect of the lidar 581 data is to correct errors in the sections of waterline containing 582 these outliers, when the snake is conditioned on both SAR and 583 lidar.

584 The effect of the second pass of the algorithm in correcting 585 the waterline position to sub-SAR pixel accuracy was also 586 assessed. For the parameter set giving the minimum rms error 587 for the snake that was conditioned on SAR and lidar data $588\left(k=3.0\right.$ and $\left.w_{l}=0.15\right)$, the algorithm was run for only the 589 first pass. The minimum rms error was $58.1 \mathrm{~cm}$, which is 590 only slightly higher than the $55.5 \mathrm{~cm}$ that was achieved when 591 both passes were employed. There was slightly more difference 592 when $k$ was raised to 4.0 and when the rms error increased to 59370.8 from 63.7. This indicates that the main reduction in error is 594 being generated in the first pass and that the second gives only 595 a second-order improvement. This may be partly because only 596 snake nodes on low slopes have been selected, and thus, height 597 differences across the SAR pixel, due to its size, will be small.
TABLE II

Frequency TABles of the ABSOLUte DifFerences of PAired Heights for the Parameter Sets Giving the Minimum RMS ERRORS FOR THE SNAKE CONDITIONED ON ONLY THE SAR DATA AND THE SNAKE CONDITIONED ON SAR AND LIDAR DATA

\begin{tabular}{|l|c|c|c|c|c|c|c|c|}
\hline & $\begin{array}{c}0- \\
49 \mathrm{~cm}\end{array}$ & $\begin{array}{c}50- \\
99 \mathrm{~cm}\end{array}$ & $\begin{array}{c}100- \\
149 \mathrm{~cm}\end{array}$ & $\begin{array}{c}150- \\
199 \mathrm{~cm}\end{array}$ & $\begin{array}{c}200- \\
249 \mathrm{~cm}\end{array}$ & $\begin{array}{c}250- \\
299 \mathrm{~cm}\end{array}$ & $\begin{array}{c}300- \\
499 \mathrm{~cm}\end{array}$ & $>=500 \mathrm{~cm}$ \\
\hline $\begin{array}{l}\text { Snake } \\
\text { conditioned } \\
\text { on SAR data } \\
(k=2.0)\end{array}$ & 155 & 20 & 9 & 3 & 3 & 1 & 3 & 6 \\
\hline $\begin{array}{l}\text { Snake } \\
\text { conditioned } \\
\text { on SAR and } \\
\begin{array}{l}\text { LiDAR data } \\
\left(k=3.0, w_{l}=\right. \\
0.15)\end{array}\end{array}$ & 154 & 20 & 9 & 5 & 2 & 1 & 0 & 0 \\
\hline
\end{tabular}

VI. DISCUSSION

The method may be applied to the validation of the flood 599 models of other river reaches, with the only prerequisites 600 additional to the usual data required to set up a hydraulic 601 model (e.g., an inflow hydrograph and river channel cross- 602 sectional data) being the availability of SAR imagery of the 603 river in flood and reasonably contemporaneous lidar data of 604 the unflooded reach. It would be relatively straightforward to 605 make the procedure operational. Lidar data are now often used 606 to parameterize the hydraulic model, making it more likely that 607 they would also be available to improve the SAR waterline. 608 It would be straightforward to implement the modified algo- 609 rithm within the Psnake NT software package. For this catch- 610 ment, the algorithm processing time was less than 1 min on a 611 Pentium IV personal computer.

The emphasis in the foregoing has been on ERS satellite 613 SAR data because of the availability of simultaneous ERS SAR 614 and aerial photography of the 1992 Oxford flood. While ERS 615 SAR data have poorer resolution than airborne lidar data, the 616 technique should also be applicable in cases where the SAR 617 resolution is similar to that of the lidar (e.g., airborne SAR), 618 in which case a second pass of the algorithm would certainly 619 be unnecessary. The algorithm of [18] and [19] has been used 620 to delineate flood extents in airborne SAR imagery [33], [34]. 621 However, given the increasing number of satellite SAR sensors 622 flying or planned and the difficulty of flying aircraft in poor 623 weather often accompanying floods, satellite SARs are likely 624 to remain to be a major source of SAR data for flood mapping 625 in the future. While the ERS SAR sensor has single VV polar- 626 ization and a fixed $23^{\circ}$ viewing angle, the advent of later sensors 627 with higher resolutions, multiple polarizations, and variable 628 viewing angles (e.g., RADARSAT and Envisat Advanced SAR) 629 has allowed improved flood delineation (e.g., [15]). The high- 630 resolution satellite SAR sensors due for launch shortly (e.g., 631 RADARSAT-2, TerraSAR, and the Cosmo-Skymed constella- 632 tion) will have resolutions that match or almost match that of 633 airborne lidar.

Production of a more smoothly varying waterline may allow 635 the development of improved performance measures for flood 636 extent validation based on patterns of height differences be- 637 tween observed and modeled waterlines rather than on patterns 638 of wet or dry pixels, as currently done. Aronica et al. [24] 639 


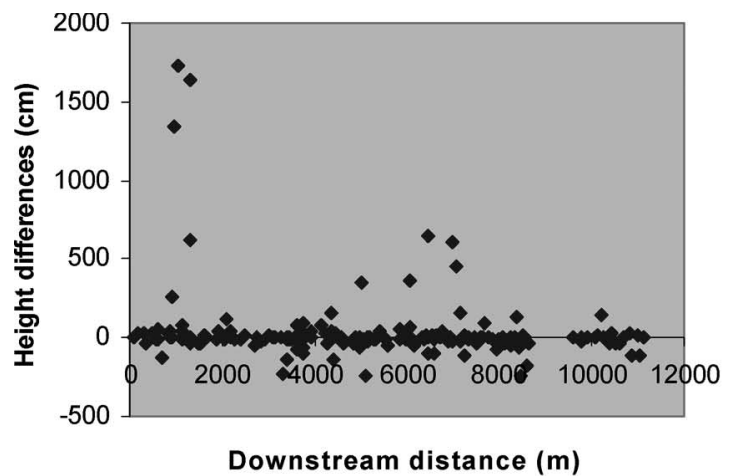

(a)

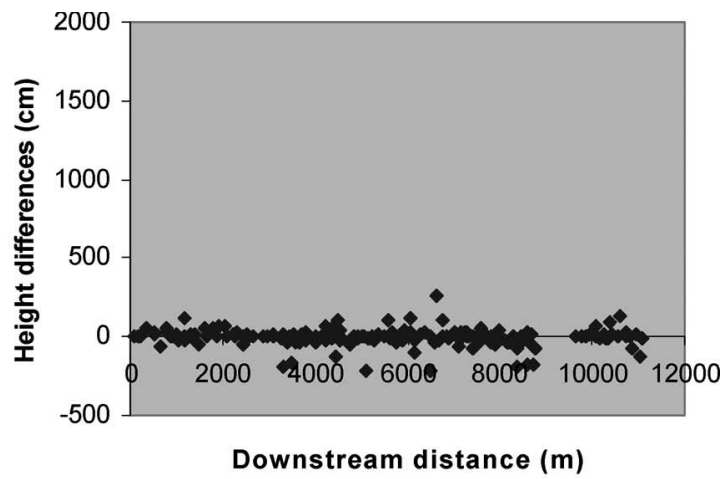

(b)

Fig. 8. Paired height differences versus distance downstream for the parameter sets giving the minimum rms errors for the snake that was conditioned on (a) SAR data and (b) SAR and lidar data.

640 describe current performance measures based on binary pat641 terns. One measure representative of these is

$$
F^{(2)}=\left(A_{\text {obs }} \bigcap A_{\text {mod }}\right) /\left(A_{\text {obs }} \bigcup A_{\text {mod }}\right)
$$

642 where $A_{\text {obs }}$ and $A_{\text {mod }}$ represent the set of pixels that are ob643 served to be inundated and predicted as inundated, respectively. $644 F^{(2)}$ is equal to 1 when observed and predicted areas coincide 645 exactly and equal to 0 when no overlap between predicted and 646 observed areas exists. A performance measure based on height 647 differences might have several advantages over one such as $648 F^{(2)}$ based on binary pattern data. First, as the distribution of $649 t$ is known, it is possible to estimate the probability $P\left(t>\left|t_{0}\right|\right)$ 650 of obtaining a $t$ value that is greater than the absolute value 651 of that measured $\left(t_{0}\right)$, whereas $F^{(2)}$ is simply a weight factor. 652 Second, the height difference measure between two model 653 runs with different parameter settings might turn out to be 654 more sensitive than $F^{(2)}$, because a small change in mean 655 height might cause a large change in $P\left(t>\left|t_{0}\right|\right)$ yet only a 656 small change in $F^{(2)}$. Third, the sign of the $t$ value identifies 657 whether an overprediction or an underprediction has occurred, 658 whereas $F^{(2)}$ may give similar values for overprediction and 659 underprediction.

660 In this case, the parameters of the snake that was generated 661 using SAR and lidar have been optimized using the aerial 662 photo waterline, but this will not be available in the more usual 663 situation in which the snake is being used to validate a model 664 waterline. It is interesting that, for those nodes in areas of low 665 slope and low vegetation, the standard deviation of their heights 666 relative to their local mean height (within an $0.5-\mathrm{km}$ distance) 667 is a minimum at the same parameter setting at which the rms 668 error of height differences between snake and aerial photo 669 waterlines is minimized [Table I(b) and (c)]. This presumably 670 reflects the fact that the snake is most smoothly varying when 671 the relative height standard deviation is minimized, and it may 672 be possible to use this measure as a surrogate for optimizing the 673 snake parameters when using the snake to validate a modeled 674 flood extent. However, a more likely scenario is that a single 675 optimum parameter set would not be sought in this situation. In 676 flood model validation, emphasis is now placed on associating 677 uncertainties with model flood extents, by deriving flood extent probability maps showing the probability of each pixel being 678 flooded, given a flood event of the given magnitude. It has 679 been found that, for a particular event, many different sets 680 of model parameters may give flood extents that match the 681 observed extent to a greater or lesser degree. Such equifinality 682 has been well documented and has resulted in the development 683 of the generalized likelihood uncertainty estimation (GLUE) 684 technique, whereby many model runs are carried out, spanning 685 the likely ranges of model parameters [35]. A flood extent 686 probability map is obtained by performing a weighted average 687 of the binary-valued modeled flood extents (with the value for 688 a pixel being 1 for flooded and 0 for not flooded), with each 689 model flood extent being weighted according to its performance 690 measure relative to an observed flood extent. As previously 691 mentioned, the performance measure could be based on pat- 692 terns of height differences between observed and modeled 693 waterlines rather than on patterns of wet or dry pixels. To date, 694 the GLUE methodology has been mainly used to assess flood 695 extent uncertainty due to model parameter errors (see, e.g., [21] 696 and [36]). However, it seems a natural future step to try to 697 extend the method to cope with uncertainty in both model and 698 snake algorithm parameters [36]. Some method of limiting the 699 number of model runs that are required would probably need to 700 be employed (e.g., Gaussian emulation [37]), although some 701 reduction might result from using an improved performance 702 measure based on height differences.

\section{CONCLUSION}

An algorithm has been developed for the automatic 705 extraction of flood extent using a snake that was generated 706 from combined SAR and lidar data, and the resulting waterline 707 compared to that generated using SAR data alone. From the re- 708 sulting snakes, sets of nodes in areas of low slope and low veg- 709 etation have been extracted, followed by further thinning. After 710 optimization of parameters, the heights of the resulting node set 711 from the snake that was conditioned on SAR and lidar matched 712 the corresponding node heights from the aerial photo waterline 713 significantly more closely than those from the snake that was 714 conditioned solely on SAR data. The conclusion is that, for 715 the variety of situations that are present in this particular 716 
717 data set, the use of the lidar data has resulted in an observed 718 waterline that varies more smoothly along the reach and is a 719 better match to our best estimate of the true waterline heights.

\section{ACKNOWLEDGMENT}

721 The authors would like to thank the EA for the provision 722 of lidar data, CEH Wallingford for the SAR and photographic 723 data, and the referees for their improvements to this paper.

724

725

\section{REFERENCES}

[1] P. D. Bates, M. S. Horritt, C. N. Smith, and D. C. Mason, "Integrating remote sensing observations of flood hydrology and hydraulic modeling," Hydrol. Process., vol. 11, no. 14, pp. 1777-1795, 1997.

[2] L. C. Smith, "Satellite remote sensing of river inundation area, stage and discharge: A review," Hydrol. Process., vol. 11, no. 10, pp. 14271439, 1997.

[3] F. T. Ulaby, R. K. Moore, and A. K. Fung, Microwave Remote Sensing, vol. 3. Norwood, MA: Artech House, 1986.

4] J.-S. Lee and I. Jurkevich, "Coastline detection and tracing in SAR images," IEEE Trans. Geosci. Remote Sens., vol. 28, no. 4, pp. 662-668, Jul. 1990.

[5] D. C. Mason and I. J. Davenport, "Accurate and efficient determination of the shoreline in ERS-1 SAR images," IEEE Trans. Geosci. Remote Sens., vol. 34, no. 5, pp. 1243-1253, Sep. 1996.

[6] J. A. Richards, P. W. Woodgate, and A. K. Skidmore, "An explanation of enhanced radar backscattering from flooded forests," Int. J. Remote Sens., vol. 8, no. 7, pp. 1093-1100, 1987.

[7] F. M. Henderson, "Environmental factors and the detection of open surface water using X-band radar imagery," Int. J. Remote Sens., vol. 16, no. 13, pp. 2423-2437, 1995.

[8] S. I. Solomon, "Methodological considerations for the use of ERS-1 SAR imagery for the delineation of river networks in tropical forest areas," in Proc. 1st ERS-1 Symp., Frascati, Italy, Jun. 26-27, 1995, pp. 595-600.

[9] M. S. Horritt, D. C. Mason, D. M. Cobby, I. J. Davenport, and P. D. Bates, "Waterline mapping in flooded vegetation from airborne SAR imagery," Remote Sens. Environ., vol. 85, no. 3, pp. 271-281, May 2003.

10] Y. Wang, L. L. Hess, S. Filoso, and J. M. Melack, "Understanding the radar backscattering from flooded and non-flooded Amazonian forests: Results from canopy backscatter modelling," Remote Sens. Environ., vol. 54, no. 3, pp. 324-332, Dec. 1995.

1] M. Badji and S. Dautrebande, "Characterisation of flood inundated areas and delineation of poor drainage soil using ERS-1 SAR imagery," Hydrol. Process., vol. 11, no. 10, pp. 1441-1450, 1995.

12] M. L. Imhoff, C. Vermillion, M. H. Story, A. M. Choudhury, A. Gafoor, and F. Poclyn, "Monsoon flood boundary delineation and damage assessment using space borne imaging radar and Landsat data," Photogramm. Eng. Remote Sens., vol. 53, no. 4, pp. 405-413, 1987.

13] H. Liu and K. C. Jezek, "Automated extraction of coastline from satellite imagery by integrating Canny edge detection and locally adaptive thresholding method," Int. J. Remote Sens., vol. 25, no. 5, pp. 937-958, 2004.

4] A. Niedermeier, E. Romaneessen, and S. Lehner, "Detection of coastlines in SAR images using wavelet methods," IEEE Trans. Geosci. Remote Sens., vol. 38, no. 5, pp. 2270-2281, Sep. 2000.

5] Y. Yu and S. T. Acton, "Automated delineation of coastline from polarimetric SAR imagery," Int. J. Remote Sens., vol. 25, no. 17, pp. 3423-3438, Sep. 2004.

16] P. A. Brivio, R. Colombo, M. Maggi, and R. Tomasoni, "Integration of remote sensing data and GIS for accurate mapping of flooded areas," Int. J. Remote Sens., vol. 23, no. 3, pp. 429-441, Feb. 2002.

17] G. Nico, M. Pappalepore, G. Pasquariello, A. Refice, and S. Samarelli, "Comparison of SAR amplitude vs. coherence flood detection methods-A GIS application," Int. J. Remote Sens., vol. 21, no. 8, pp. 1619-1631, May 2000.

$18]$ M. S. Horritt, "A statistical active contour model for SAR image segmentation," Image Vis. Comput., vol. 17, no. 3/4, pp. 213-224, Mar. 1999.

19] M. S. Horritt, D. C. Mason, and A. J. Luckman, "Flood boundary delineation from synthetic aperture radar imagery using a statistical active contour model," Int. J. Remote Sens., vol. 22, no. 13, pp. 2489-2507, Sep. 2001.

20] G. Schumann, R. Hostache, C. Puech, L. Hoffmann, P. Matgen, F. Pappenberger, and L. Pfister, "High-resolution 3D flood information from radar imagery for flood hazard management," IEEE Trans. Geosci. 786 Remote Sens., vol. 45, no. 6, pp. 1715-1725, Jun. 2007.

[21] F. Pappenberger, K. Beven, M. Horritt, and S. Blazkova, "Uncertainty in 788 the calibration of effective roughness parameters in HEC-RAS using inun- 789 dation and downstream level observations," J. Hydrol., vol. 302, no. 1-4, 790 pp. 46-69, 2005.

[22] D. C. Mason, D. M. Cobby, M. S. Horritt, and P. D. Bates, "Flood- 792 plain friction parameterization in two-dimensional river flood models 793 using vegetation heights derived from airborne scanning laser altimetry," 794 Hydrol. Process., vol. 17, no. 9, pp. 1711-1732, 2003.

[23] D. M. Cobby, D. C. Mason, M. S. Horritt, and P. D. Bates, "Two- 796 dimensional hydraulic flood modelling using a finite element mesh de- 797 composed according to vegetation and topographic features derived from 798 airborne scanning laser altimetry," Hydrol. Process., vol. 17, no. 10, 799 pp. 1979-2000, 2003.

[24] G. Aronica, P. D. Bates, and M. S. Horritt, "Assessing the uncertainty in 801 distributed model predictions using observed binary pattern information 802 within GLUE," Hydrol. Process., vol. 16, no. 10, pp. 2001-2016, 2002.803

[25] D. S. Biggin and K. Blyth, "A comparison of ERS-1 satellite radar and 804 aerial photography for river flood mapping," J. Chart. Inst. Water Eng. 805 Manag., vol. 10, pp. 1777-1795, 1996.

[26] L. M. G. Pereira and L. L. F. Janssen, "Suitability of laser data for DEM 807 generation: A case study in the context of road planning and design," 808 ISPRS J. Photogramm. Remote Sens., vol. 54, no. 4, pp. 244-253, 1999.809

[27] I. J. Davenport, N. Holden, and R. J. Gurney, "Characterizing errors 810 in airborne laser altimetry data to extract soil roughness," IEEE Trans. 811 Geosci. Remote Sens., vol. 42, no. 10, pp. 2130-2141, Oct. 2004.

[28] D. J. Williams and M. Shah, "A fast algorithm for active contours and 813 curvature estimation," CVGIP, Image Underst., vol. 55, no. 1, pp. 14-26, 814 Jan. 1992.

[29] J. Ivins and J. Porrill, "Statistical snakes: Active region models," in 816 Proc. 5th Brit. Mach. Vis. Conf., York, U.K., Sep. 1994, vol. 1 and 2, 817 pp. 377-386.

[30] M. S. Horritt, "Psnake NT user manual," Univ. Bristol, Bristol, U.K., 819 2002. School of Geographical Sciences Report.

[31] D. C. Mason, T. R. Scott, and H.-J. Wang, "Extraction of tidal channel 821 networks from airborne lidar data," ISPRS J. Photogramm. Remote Sens., 822 vol. 61, no. 2, pp. 67-83, 2006.

[32] C. V. Deutsch and A. Journel, GSLIB: Geostatistical Software Library and 824 Users's Guide. New York: Oxford Univ. Press, 1992, p. 41.

[33] P. D. Bates, M. Wilson, M. S. Horritt, D. C. Mason, N. Holden, and 826 A. Currie, "Reach scale floodplain inundation dynamics observed using 827 airborne SAR imagery," J. Hydrol., vol. 328, no. 1/2, pp. 306-318, 2006. 828

[34] S. Neelz, G. Pender, I. Villanueva, M. D. Wilson, N. G. Wright, 829 P. D. Bates, D. C. Mason, and C. Witlow, "Using remotely sensed 830 data to support flood modelling," Proc. Inst. Civil Eng., vol. 159, no. 1, 831 pp. 35-44, 2006.

[35] K. J. Beven and A. M. Binley, "The future of distributed models: Model 833 calibration and predictive uncertainty," Hydrol. Process., vol. 6, no. 3, 834 pp. 279-298, 1992.

[36] M. S. Horritt, "A methodology for the validation of uncertain flood inun- 836 dation models," J. Hydrol., vol. 326, no. 1-4, pp. 153-165, 2006.

[37] J. E. Oakley and A. O'Hagan, "Probabilistic sensitivity analysis of com- 838 plex models: A Bayesian approach," J. R. Stat. Soc., Series B, vol. 66, 839 no. 3, pp. 751-769, Aug. 2004.

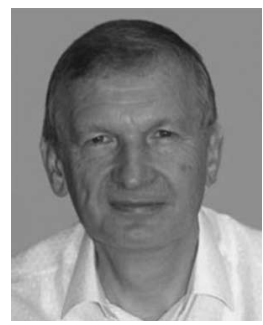

David C. Mason received the B.Sc. and Ph.D. de- 841 grees in physics from the University of London, 842 London, U.K., in 1963 and 1968, respectively. 843

He was with the U.K. Medical Research Coun- 844 cil and Plessey Electronic Systems Research. Since 845 1984, he has been with the Natural Environment 846 Research Council Environmental Systems Science 847 Centre, University of Reading, Reading, U.K., carry- 848 ing out research on the automated extraction of infor- 849 mation from remotely sensed data and linking these 850 data to environmental models. His current research 851 interests include using remotely sensed data for validation and parameterization 852 of river flood models and assimilation into coastal morphodynamic models. 853 


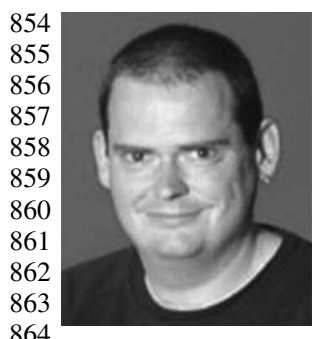

Matthew S. Horritt received the Ph.D. degree from the University of Reading, Reading, U.K., in 1998.

He was with the University of Leeds, Leeds, U.K., and the Department of Civil Engineering, University of Bristol, Bristol, U.K., as a Postdoctoral Research Fellow and a Lecturer in civil engineering, respectively. $\mathrm{He}$ is currently a Specialist Modeler with Halcrow Group Ltd., London, U.K. His research interests are flood inundation models, remote sensing of floods and floodplain topography, and model validation.

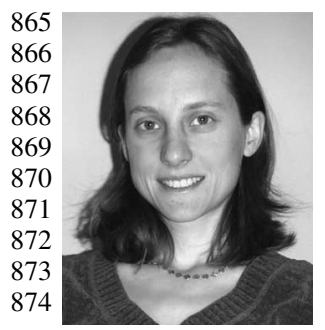

Johanna T. Dall'Amico is currently working toward the B.Sc. degree in mathematics at the University of Reading, Reading, U.K., and a Diploma in geography and remote sensing at Ludwig-Maximilian University of Munich, Munich, Germany.

She is a Visiting Student at the Natural Environment Research Council Environmental Systems Science Centre, University of Reading, where she works on remote sensing applications for fluvial flood models.

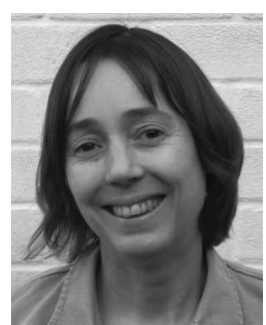

Tania R. Scott received the B.Sc. degree in 875 astronomy from the University of Canterbury, 876 Christchurch, New Zealand, in 1992 and the 877 $\mathrm{Ph}$.D. degree in astronomy from the University of 878 Cambridge, Cambridge, U.K., in 1998.

She was with the U.K. Met Office, where she 880 developed meteorological products for the aviation 881 industry to address safety and environmental issues. 882 She is currently with the Natural Environment 883 Research Council (NERC) Environmental Systems 884 Science Centre, University of Reading, Reading, 885 U.K., where she is interested in using remote sensing data in aid of environ- 886 mental modeling. Her current project is to apply data assimilation techniques 887 to coastal area morphodynamic modeling, which is funded under the NERC 888 program Flood Risk from Extreme Events.

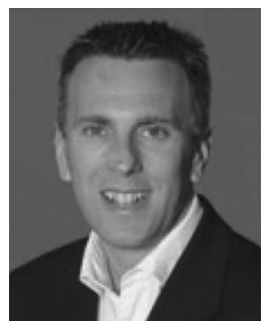

Paul D. Bates received the Ph.D. degree from the 890 University of Bristol, Bristol, U.K., in 1993, with 891 support from a Natural Environmental Research 892 Council studentship.

Subsequently, he has been with at the Univer- 894 sity of Bristol as a Postdoctoral Researcher and 895 Lecturer, and has been a Full Professor since 896 2003. He is currently the Director of the Hydrology 897 Research Group, School of Geographical Sciences, 898 University of Bristol. He has been a Visiting Sci- 899 entist at Princeton University, Laboratoire National 900 D'Hydraulique, Paris, and the EU Joint Research Centre, Ispra, Italy. His 901 research interests include the development and analysis of numerical models for 902 predicting river flood flows, principally using data derived from remote sensing 903 sources, spatial prediction, risk, and uncertainty. He is the Editor-in-Chief of 904 the International Journal of River Basin Management. 